\title{
Writing to Learn and Learning to Write across the Disciplines: Peer-to-Peer Writing in Introductory-Level MOOCs
}
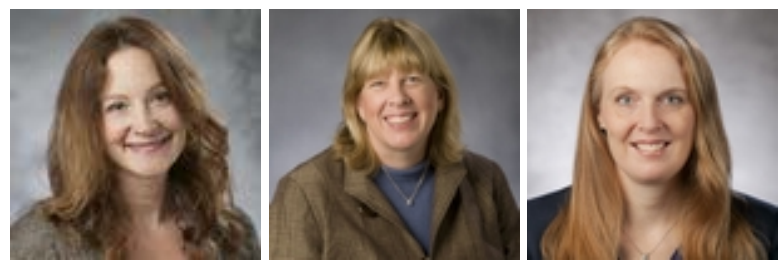

Denise K. Comer, Charlotte R. Clark, and Dorian A. Canelas Duke University, USA

\section{Abstract}

This study aimed to evaluate how peer-to-peer interactions through writing impact student learning in introductory-level massive open online courses (MOOCs) across disciplines. This article presents the results of a qualitative coding analysis of peer-topeer interactions in two introductory level MOOCs: English Composition I: Achieving Expertise and Introduction to Chemistry. Results indicate that peer-to-peer interactions in writing through the forums and through peer assessment enhance learner understanding, link to course learning objectives, and generally contribute positively to the learning environment. Moreover, because forum interactions and peer review occur in written form, our research contributes to open distance learning (ODL) scholarship by highlighting the importance of writing to learn as a significant pedagogical practice that should be encouraged more in MOOCs across disciplines.

Keywords: Open learning; higher education; online learning; massive open online courses 


\section{Introduction}

Massive open online courses (MOOCs) could be poised to transform access to higher education for millions of people worldwide (Waldrop, 2013). From a pedagogical standpoint, the sheer scale of these courses limits the extent of student-instructor interpersonal contact, and this leads to a central question involving how a reliance on peer interaction and review impacts student learning. Student-student interaction, once called "the neglected variable in education" (Johnson, 1981), is now recognized as a fundamental high-impact practice in education (Salomon \& Perkins, 1998; Chi, 2009). Clearly humans interact via multiple modes, including in person, but also more and more frequently via long-distance digital communication such as by telephone, email, social media websites, online chats and forums, video conferencing, and blogs; all of these modes are emerging in modern pedagogies. To this end, deWaard et al. cite "dialogue as a core feature of learning in any world, whether face-to-face or digital" (deWaard et al., 2014). In fact, in face-to-face and smaller-scale online learning contexts, peer-to-peer dialogues have been shown to be critical to developing deep conceptual understanding (Chi, 2009). In MOOCs, peer-to-peer dialogues occur primarily through writing: in forums and via peer-reviewed assignments.

MOOCs, because of their scale, offer a significant opportunity for peer-to-peer interaction in the form of dialogic, networked learning experiences (Clarà \& Barberà, 2013). However, also because of their scale and the diversity of student learners enrolled, MOOCs present substantial challenges in this domain (Kim, 2012). Some scholars have suggested that MOOCs limit or underestimate the importance of interpersonal engagement for learning (Kolowich, 2011; Kim, 2012; Pienta, 2013). Questions about how or whether to facilitate interpersonal engagement in MOOCs have particular importance since the majority of MOOC learners are adults (Guo \& Reinecke, 2014). Research maintains that constructivist approaches to learning are especially effective with adult learners (Huang, 2002; Ruey, 2010). It is within this context that we endeavor to examine one of the key questions concerning the efficacy of MOOCs: How can interactive learning be promoted and assessed in this context?

Any exploration of this question, though, also demands an inquiry into writing. The primary mechanisms for student interaction in MOOCs occur through writing in course forums and peer reviewed assignments. ${ }^{1}$ The act of writing has been identified as a highimpact learning tool across disciplines (Kuh, 2008), and efficacy in writing has been shown to aid in access to higher education and retention (Crosling, Thomas, \& Heagney, 2007). Writing has also been shown to be effective in the promotion of learning and student success in relatively large enrollment face-to-face courses (Cooper, 1993; Rivard, 1994; Reynolds et al., 2012). Research suggests that writing instruction in online settings can provide enhanced learning experiences and opportunities for pedagogical

${ }^{1}$ In some cases dialogic interaction occurs verbally through video chats in such platforms as Google Hangouts. 
reflection (Boynton, 2002). Moreover, across educational disciplines and compared to face-to-face dialogues in time-limited classroom settings, written, time-independent online discourse has been shown to lead to more reflective contributions by participants (Hawkes, 2001; Bernard, 2004). Research also suggests that written dialogue in online courses contributes to the development of students' critical reasoning skills (Garrison, 2001; J oyner, 2012).

Given the complex ways in which writing intersects with participant interaction in MOOCs, it is of crucial importance to examine how writing impacts the MOOC learning experience. Writing, in fact, may be a key dimension for forging intersections between MOOCs and more traditional higher education contexts. That is, amidst ongoing debates about the promise or threat of MOOCs to higher education more broadly, perhaps writing offers a point of reciprocal research, where we can learn more about the role of writing in learning across higher education contexts, from open distance learning to face-to-face settings and all the hybrid and shifting contexts in between.

Herein, we examine two separate introductory-level MOOCs: one in the humanities, English Composition I: Achieving Expertise (March 18, 2013-J une 10, 2013), ${ }^{2}$ taught by Denise Comer through Duke University and Coursera, and one in the natural sciences, Introduction to Chemistry (J anuary 20, 2014-April 6, 2014), taught by Dorian Canelas through Duke University and Coursera. Although at first glance these courses might seem unrelated, common threads weave them together into a research project: both specifically target introductory students; focus on critical thinking and writing-to-learn to develop expertise; foster key skills for access to fields in higher education; and employ a combination of video lectures and quizzes along with formal writing assignments and informal written communication via forums. We specifically chose to conduct research across disciplines because we wanted to contribute to emerging MOOC literature that examines how disciplinarity impacts MOOC pedagogy and learning outcomes dimensions (Adamopoulos, 2013; Cain, 2014).

The main objective of this study was to evaluate how peer-to-peer interactions through writing impact student learning in introductory-level MOOCs across disciplines. Specifically, we explored the following research questions:

- How do peer-to-peer interactions through writing impact student learning in introductory-level writing and chemistry MOOCs?

- What is the impact of peer-to-peer writing on engaging students in MOOC coursework who identify as less academically-prepared and less self-motivated?

- How can peer-to-peer writing function as a metric to assess student success in MOOC delivered introductory writing and science coursework?

\footnotetext{
${ }^{2}$ English Composition was funded largely through a grant from the Bill \& Melinda Gates Foundation.
} 
Our research draws on several related strands of scholarship: writing-to-learn theory, online writing theory; science, technology, engineering, and mathematics (STEM) pedagogy; and emerging MOOC research. Our research contributes to scholarship on open distance learning (ODL) by examining the role of writing as a high impact educational practice in MOOCs across disciplines.

Writing-to-learn is a pedagogy that actively involves students across disciplines in the construction of their own knowledge through writing (Sorcinelli \& Elbow, 1997; Carter, 2007). Peer review makes this process not only active but interactive. Student-student and student-faculty dialogues have been shown to be critical to developing a community of scholarship for enhanced learning and deep conceptual understanding among learners (Chi, 2009; Johnson, 1981). The capabilities of MOOCs make it possible to bring this active-constructive-interactive framework (Chi, 2009) to thousands of students at one time. Indeed, emerging research suggests that MOOCs have the capacity to create unique "networked learning experiences" with unprecedented opportunities for collaboration, interaction, and resource exchange in a community of learners (Kop, Fournier, \& Mak, 2011; Siemens, 2005). And, also in keeping with these findings, research has found evidence that the most successful MOOC students are typically heavy forum users (Breslow, 2013).

Given that MOOCs promise to increase access to postsecondary education (Yuan \& Powell, 2013), we are particularly interested in how peer-to-peer interactions through writing in introductory-level MOOCs impact the learning outcomes for less academically advanced and/or under-resourced learners. Although research has also indicated that MOOCs are not yet reaching less academically prepared students (Emanuel, 2013), we endeavor to learn how less academically prepared students can best learn in these introductory-level MOOCs. Research suggests that less well-prepared students can behave more passively in academic settings, relying on memorization and imitation as strategies for learning (Mammino, 2011). This has been shown to arise at least partly from lack of comfort with the use of language, particularly if trying to communicate in a non-native language (Mammino, 2011). Research in developmental writing suggests that early emphasis on writing in a student's academic career can improve retention and academic performance (Crews \& Aragon, 2004).

Learning more about how peer-to-peer interactions through writing impacts retention and academic performance is especially critical in the context of STEM. Research suggests that the greatest loss of student interest in STEM coursework occurs during the first year of college study (Daempfle, 2004). Scholarship has found that peer interactions in introductory-level science courses, especially through writing, have in some contexts doubled student retention rates in STEM disciplines (Watkins \& Mazur, 2013). Writing to learn has been used extensively in chemistry and other science disciplines and has been shown to help students confront and resolve several key barriers to and misconceptions about effective science learning (Pelaez, 2002; Vázquez, 2012; Reynolds et al., 2012). More specifically, writing with peer review has been shown 
to improve student performance, communication, and satisfaction even in large enrollment undergraduate chemistry courses (Cooper, 1993). We are curious to understand more about how these positive attributes of peer-to-peer interactions through writing will transfer to the MOOC environment and what impact, if any, they may have on student learning and retention in introductory science.

\section{Methods}

Our research involved intensive qualitative data coding from each MOOC using $\mathrm{NVivo}^{(\mathrm{TM})}$ qualitative research software. Coding was accomplished by a team of 10 trained coders (doctoral students, post-doctoral fellows, faculty) during a five-day coding workshop from 11 March 2014 - 14 March 2014. The workshop was designed and led by two researchers in the social sciences at Duke University who primarily work with qualitative methods and are also authorized trainers for QSR, International for the software program NVivo. We estimate that about 175 hours of cumulative coder time occurred during the week. Below we provide more details about our methods.

\section{Coding Protocol}

Prior to the workshop, we developed a coding protocol, with the assistance of a doctoral student and postdoctoral scholar in developmental psychology. The protocol included nodes for such items as affect, length of post, attitude, learning objectives, student challenges, and elements of writing (for full coding protocol, see Appendix A).

\section{Coding Workshop}

During the workshop, coders were first led through processes to become familiar with the structure of MOOCs in general, and our study MOOCs in particular, and with important NVivo components, including data capture, import, and coding to themes. Second, coders were introduced to the pre-designed project file and node structure, and leaders oversaw use of the protocols by team members. After this step, based on coding of the same data sources by team members, leaders examined inter-rater reliability and made adjustments to the team's work. Third, coders worked individually on various data sources as assigned. Twice a day, time was taken for team discussion, and leaders were present at all times during the coding workshop to answer individual questions.

\section{Coding Reliability}

When introducing the node structure, the coding workshop leader walked all coders through each node and its planned use. Subsequently, teams of three coders coded the same two documents to the node structure. This led to assessment of inter-rater reliability and team discussion. At several points node definitions and/ or structure were discussed as a whole group. 
Many of the nodes are what Maxwell (2005) refers to as "organizational" or "substantive" nodes, which are more topical, descriptive, or straightforward to interpret than "theoretical" coding (which is more abstract) (p. 97). Because most of the nodes have literal definitions, with a few exceptions, to which we paid close attention, we believe little room existed for coders to differ substantially from each other on inferential coding of text.

Reliability was also established through having coders collect and evaluate different types of data from different disciplines throughout the coding workshop (for a summary of items coded, please see Table 4). This form of triangulation, called "investigator triangulation" (Denzin, 2009, p. 306), involves multiple researchers in the data collection and analysis process, and the "difference between researchers can be used as a method for promoting better understanding” (Armstrong et al., 1997, p. 597).

Finally, we spent the second half of Day Five of the coding workshop having coders review nodes in the merged file for coding inconsistencies. Various coders were given a family of nodes to open and review, using NVivo queries to consider the consistency of coding that they found.

We coded data from two different areas of the MOOCs: discussion forums and peer assessments.

\section{Discussion Forum Data}

The following data (Tables 1 and 2) provide a sense of the total discussion forum volume for these courses, from which we culled our sample. Please see Appendix A for more definitions and descriptive details.

Table 1

Discussion Forum Data, English Composition I: Achieving Expertise, 2013

\begin{tabular}{|l|l|}
\hline Total views & 520,192 \\
\hline Total threads & 19,198 \\
\hline Total posts & 54,479 \\
\hline Total comments & 19,498 \\
\hline Total votes & 42,506 \\
\hline Total reputation points & 20,312 \\
\hline Number of participants posting & 11,641 \\
\hline Number of participants commenting & 5,033 \\
\hline Number of participants voting & 6,444 \\
\hline
\end{tabular}


Table 2

Discussion Forum Data, Introduction to Chemistry, 2014

\begin{tabular}{|l|l|}
\hline Total views & 107665 \\
\hline Total threads & 1874 \\
\hline Total posts & 7198 \\
\hline Total comments & 3053 \\
\hline Total votes & 6777 \\
\hline Total reputation points & 2752 \\
\hline Number of participants posting & 1645 \\
\hline Number of participants commenting & 709 \\
\hline Number of participants voting & 858 \\
\hline
\end{tabular}

From this total volume, we coded a sampling of two types of discussion forum data.

\section{Point in time (PIT) and general peer-to-peer (P2P) discussion forum posts.}

We coded 35 full discussion forum threads in Weeks One, Four, and Seven of both courses. In addition, we coded 35 full threads from Week 12 for English Composition (the Chemistry course was not 12 weeks long.) We also coded general forum posts for both courses.

\section{Top poster P2P discussion forum posts.}

We captured all activities of the top three posters in each of the two courses and coded a sample of these posts. (See Table 3 for top three posters in each course and statistics.)

Table 3

Top Posters in Each Course (All Forum Activity) on Date of Coding Session

\begin{tabular}{|l|l|}
\hline $\begin{array}{c}\text { Top posters in Chemistry (number of } \\
\text { posts) }\end{array}$ & $\begin{array}{c}\text { Top posters in English Composition (number of } \\
\text { posts) }\end{array}$ \\
\hline Student A (571) & Student D (539) \\
\hline Student B (133) & Student E (306) \\
\hline Student C (64) & Student F (21) \\
\hline
\end{tabular}




\section{Peer Assessment Data}

In addition to coding data from discussion forums, we also coded data from peer assessments in each course. Students provided feedback on other students' writing for both courses. We did not code the assignments themselves.

\section{Peer assessment sources in Chemistry.}

In Chemistry, this feedback was located in a specially designated open forum for peer review of a writing assignment. Students in the Chemistry class submitted an essay on a chemistry-related topic of their choice to the peer-review tool (see Appendix B). Coursera then randomly assigned each submission to be read and commented upon by two peers according to a rubric (see Appendix C). After the first student had reviewed a peer's essay by entering their feedback as written comments, Coursera automatically populated a designated forum with the essay and anonymous peer review, whereupon any additional anonymous peer reviews would appear over time and more students could read and comment on each essay. Seven hundred and fourteen students submitted this assignment and received peer feedback. We coded evaluations on 120 submissions (16.8 percent of the total volume of submissions), randomly selected by capturing every 6th submission with correlating feedback on the Chemistry peer assessment forum.

\section{Peer assessment sources in English Composition.}

We reviewed three different types of English Composition peer-assessment data.

1. Peer feedback on a brief introductory essay, "I Am A Writer," posted to a specially designated open forum (see Appendix D). This first introductory writing activity, designed to facilitate conversations about writing among the community of learners, was conducted on the forums as opposed to through the formal peer-assessment mechanism. Thus, students could voluntarily respond to as few or as many peers' submissions as they wanted. Approximately 8,000 students posted the "I Am A Writer" assignment. We chose to capture feedback on 80 peer responses, which amounts to feedback on about $1 \%$ of the submissions. This was roughly equivalent to taking the first submission from each page of posts on the designated "I am a Writer" forum for a random sample.

2. Peer feedback provided through the formal peer-assessment mechanism. For each of the four major writing projects in English Composition (see Appendix E), students submitted a draft and a revision to the formal peer-assessment mechanism in Coursera. For each project, Coursera randomly distributed each student's draft submission to three peers in order to receive "formative feedback" according to a rubric. Then, each student's final version was randomly distributed to four other peers in order to receive "evaluative feedback" according to a rubric. 
Formative and evaluative peer feedback rubrics included a series of specific questions as well as several open-ended questions (see Appendix F). ${ }^{3}$ We only coded data from questions that seemed relevant to peer-to-peer interaction, namely,

- What did you like best about this essay?

- What did you learn about your writing/your own project based on responding to this writer's essay/ project?

- What overall comments do you have for the writer as he or she moves on to project $2 /$ project $3 /$ project $4 /$ beyond the course?

These peer-assessment submissions and feedback were private for students, and so in this case, as required by Duke University's Internal Review Board, the only student submissions evaluated were those from students who approved our use of these data. Throughout the course, the students provided 14,682 separate project peer assessment feedbacks. Approximately 250 students gave permission for their work to be included in this research process. We coded a random sample of the feedback provided by 50 of these students, which amounted to 342 project peer-assessment feedbacks.

This data enabled us to look at feedback on a student-by-student basis (as opposed to assignment by assignment).

3. Comments about peer feedback written in final reflective essays. Students in English Composition compiled portfolios of their writing at the end of the course. These portfolios consisted of drafts and revisions of each of the four major projects as well as a final reflective essay in which students made an argument about their progress toward the learning objectives of the course (see Appendix G). One thousand four hundred and fifteen students completed final reflective essays; approximately 250 students gave permission for their final reflective essays to be included in the research process. We coded comments about their experiences providing and receiving peer feedback in 48 of these final reflective essays.

Table 4 shows the total number of items coded for each type of source.

3 These formative and evaluative rubrics were developed largely through a consultation with assessment expert Edward White. 
Table 4

Number of Items Coded and Scores Collected

\begin{tabular}{|c|c|c|c|c|c|c|}
\hline \multirow{2}{*}{ Forum postings } & \multicolumn{2}{|c|}{ Chemistry } & \multicolumn{2}{|c|}{$\begin{array}{l}\text { English } \\
\text { Composition }\end{array}$} & \multicolumn{2}{|l|}{ Total } \\
\hline & Sources ${ }^{4}$ & Posts 5 & Sources & Posts & Sources & Posts \\
\hline Top posters & 3 & 85 & 3 & 209 & 6 & 294 \\
\hline Forums & 124 & 1344 & 206 & 1051 & 330 & 2385 \\
\hline General forums & 25 & 809 & 37 & 86 & 63 & 895 \\
\hline Points in time & 99 & 535 & 133 & 768 & 232 & 1303 \\
\hline Week 1 & 29 & 163 & 36 & 106 & 65 & 269 \\
\hline Week 4 & 35 & 164 & 35 & 289 & 70 & 453 \\
\hline Week 7 & 35 & 208 & 27 & 169 & 62 & 377 \\
\hline Week 12 & N/A & N/A & 35 & 204 & 35 & 204 \\
\hline \multicolumn{7}{|l|}{ Peer review } \\
\hline $\begin{array}{l}\text { Writing assignment on } \\
\text { forums }^{6}\end{array}$ & 106 & 370 & 96 & 325 & 195 & 695 \\
\hline Student portfolios & N/A & $\mathrm{N} / \mathrm{A}$ & 40 & N/A & 40 & N/A \\
\hline Peer evaluations & N/A & N/A & 279 & N/A & 279 & N/A \\
\hline Self-evaluations & N/A & N/A & 39 & N/A & 39 & N/A \\
\hline
\end{tabular}

\section{Limitations}

Our research included several limitations. A primary limitation is that not all enrolled students participated by posting in the forums, so any analysis of forum posts will only include data from those students who felt motivated to post. Additional limitations include the following:

- Coders were calibrated through coding common text passages on the first day. For the rest of the coding session each piece of data was coded by individuals.

- We estimated the number of threads by multiplying 25 times the number of pages. This may be a slight overestimate, because the last page in each forum would by definition have less than 25 threads.

- Within a thread, we did not manually count the number of posts, but took the statistic from Coursera. A very small number of posts were empty or deleted by

${ }^{4}$ For forums, this was the number of threads collected. For peer review, the number of sources equals the number of individual documents collected. N/A means not applicable.

${ }^{5}$ Number of posts is the number of times someone posted to a given thread; only applicable to the forums or assignments posted to the forums.

${ }^{6}$ For Chemistry, this was the only writing assignment; For English Composition, this was the "I Am A Writer" assignment in Week 1. 
the forum moderators as spam or containing inappropriate material. Therefore, our post count may be a slight overestimate.

- We did not review student assignment submissions. We only coded the student feedback. Therefore, our coding inferences may be limited by this constraint.

- We captured threads from the website for coding using the NCapture software from NVivo. We used the Explorer browser exclusively. However, we learned that, irregularly and unpredictably, NCapture drops a line of text at a page break in the pdf. We did not try to go back and recover these lost lines of text in our analysis.

- Although we captured the number of views of each thread, we recognize that simply by entering each thread to capture it (and thereby adding a view count), we are increasing the number of views of each of our threads. To minimize this, our procedure was to document the number of views on an individual thread before actually opening the thread. Some researcher thread views are included in the overall view counts for the courses.

- Although unlikely due to the enormous number of posts to the forums, and our limited sampling frame, we may have inadvertently coded the same post twice, because we coded to various points-in-time, and we also sampled posts from the top three posters in each discipline.

\section{Results}

After the coding was completed, we ran several queries through NVivo. Below are several of the most significant results.

\section{Word Frequency Queries}

Figure 1 illustrates the 100 most common words in weekly forums in each course. The larger the word, the more commonly it appeared in the forum.

These results illustrate visually that students were staying on topic by primarily engaging in discussions that paralleled the weekly content of the courses. For example, in Chemistry, the syllabus has the following descriptions for content in weeks six and seven, respectively:

Week 6: Introduction to light, Bohr model of the hydrogen atom, atomic orbitals, electron configurations, valence versus core electrons, more information about periodicity. 
Week 7: Introduction to chemical bonding concepts including sigma and pi bonds, Lewis dot structures, resonance, formal charge, hybridization of the main group elements, introduction to molecular shapes.

Likewise illustrating the ways in which the discussion forums stayed on topic to the course content, the syllabus for English Composition includes in Weeks 6 and 7 the following text:

\author{
What is an annotated bibliography? \\ Peer Feedback: Project 2 Image Analysis \\ Sample Case Studies
}

Clearly, the overwhelming majority of peer-to-peer discussions in the forums for the English Composition and Chemistry courses studied herein are directly related to the course content. This observation offers a counterpoint to the observation by other researchers that "a substantial portion of the discussions [in MOOC forums] are not directly course related" (Brinton et al., 2013) and these data qualify the conclusion that "small talk is a major source of information overload in the forums" (Brinton et al., 2013).

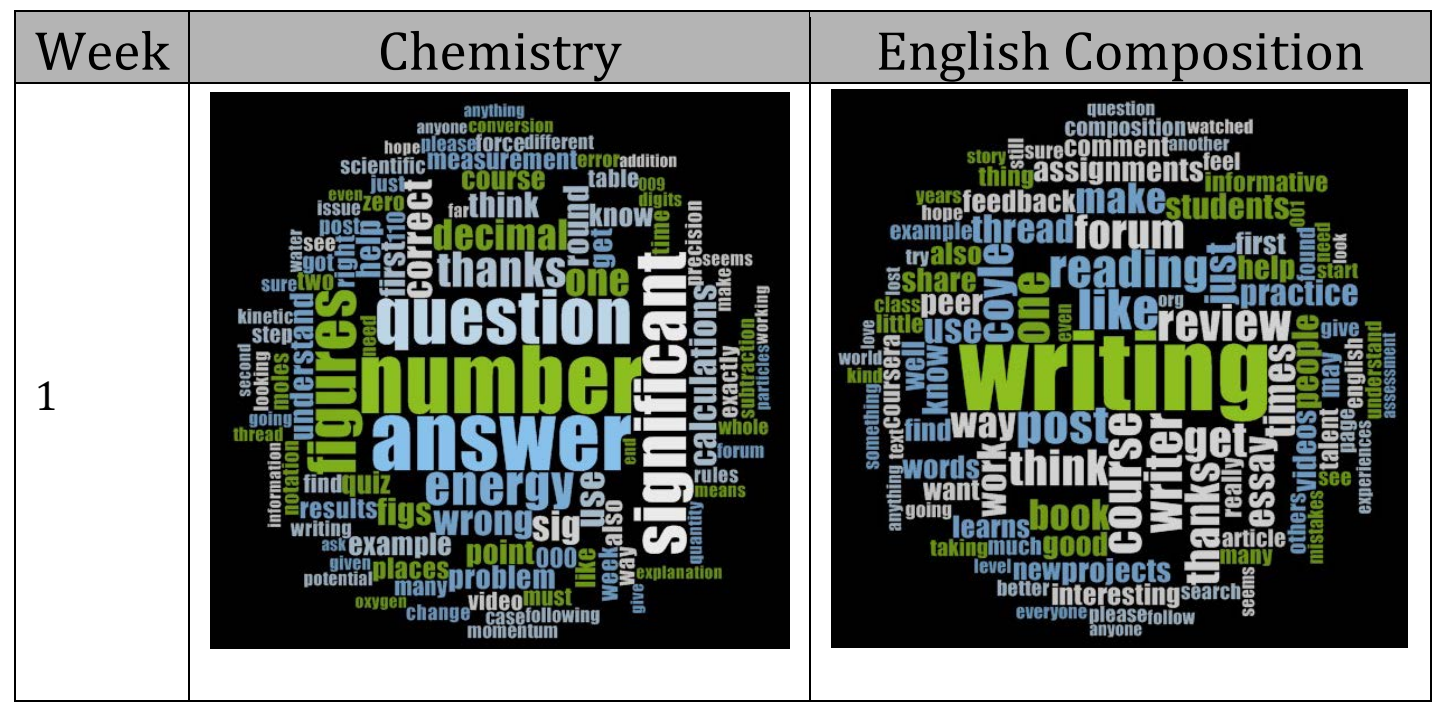




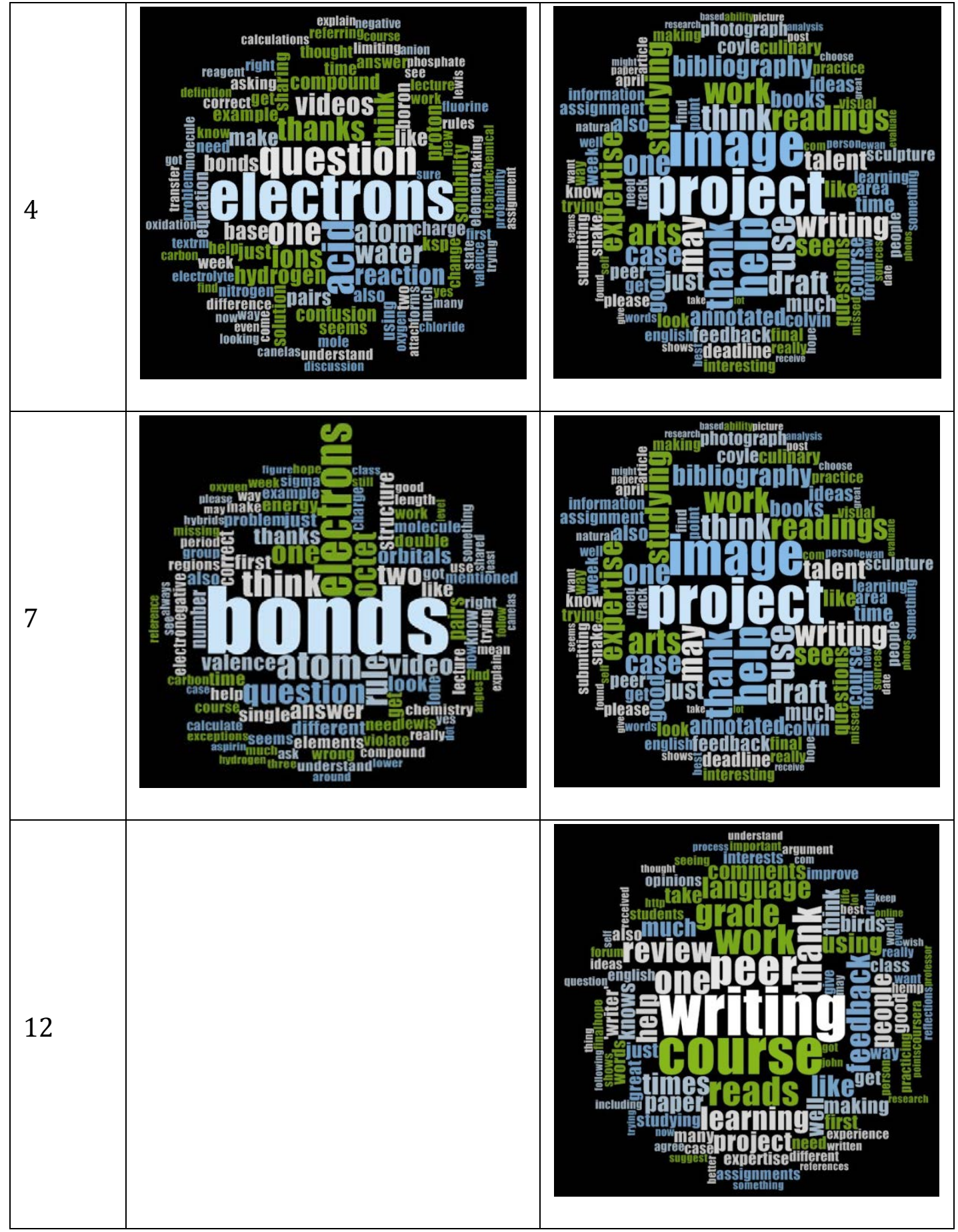

Figure 1. Word frequency in discussion forums by week. 


\section{Discussion Forum Post Length}

Table $5^{7}$ shows post length in the forums. In general, Chemistry students' posts were shorter than those of the English Composition students. The Chemistry forum included a much higher percentage of posts that were coded as very short or short; over $90 \%$ of the posts fell into these two categories. On the other hand, English Composition forums also included many posts that were coded as very short or short (approximately 60\%), but nearly $40 \%$ of the posts in this course were coded as medium or long. While Chemistry forums had about $2 \%$ of posts coded as long, English Composition had nearly $23 \%$ coded as long.

Table 5

Length of Posts in Discussion Forums

\begin{tabular}{|l|l|l|}
\hline & Chemistry forums & English Composition forums \\
\hline Very short (less than 3 lines) & $50.24 \%$ & $18.72 \%$ \\
\hline Short (3-10 lines) & $40.00 \%$ & $41.72 \%$ \\
\hline Medium (11-20 lines) & $7.92 \%$ & $16.98 \%$ \\
\hline Long (21+lines) & $1.84 \%$ & $22.58 \%$ \\
\hline
\end{tabular}

\section{Attitude}

Attitude is well established as being critically important to learning: "In order for student-student interaction to have constructive impact on learning, it must be characterized by acceptance, support, and liking" (Johnson, 1981, p. 9). Research indicates that learners' conceptions of and attitudes toward learning have a deep impact on the efficacy of online peer assessment and interactions (Yang \& Tsai, 2010).

Every post, or part of a post, if warranted, was coded as either positive, negative, or neutral (Table 6). Attitude of student writing in the forums was tracked as a function of time in the courses. Considering all coded weeks, the majority of content coded in student posts were neutral in attitude in both courses, and a relatively small percentage was coded as negative in both courses. The attitude expressed in student posts was generally more positive than negative in both courses: 2.8 times more positive than

\footnotetext{
7 These data include Point in Time forum posts and general forum posts, but exclude data collected from top posters. We chose to exclude top posters to avoid duplication of data.

${ }^{8}$ Because whole posts were always coded to length, this column shows the percentage of overall posts coded to various lengths; the sum of each column is $100 \%$.
} 
negative in Chemistry and 3.9 times more positive than negative in English Composition.

Table 6

Summary of Attitude Coding across All Weeks in Discussion Forums ${ }^{9}$

\begin{tabular}{|c|c|c|}
\hline & Chemistry all weeks ${ }^{10}$ & English Composition all weeks \\
\hline Positive & $17.17 \%$ & $27.91 \%$ \\
\hline Negative & $6.19 \%$ & $7.02 \%$ \\
\hline Neutral & $76.64 \%$ & $65.07 \%$ \\
\hline
\end{tabular}

Examples of posts coded to positive attitude:

"I am starting to understand why I am studying on a Friday evening for the first time in my entire life. :)"

"I appreciate all the hard work that my reviewers went to ... thank you!"

Example of posts coded to negative attitude:

"Go for it (un-enrole) [sic]- [two names removed]. You both know too much already and you obviously have nothing to gain from this course. You'll be doing us "stupid" students a favor."

The tenor of posts across all weekly forums was coded as slightly more positive in English Composition than in Chemistry (27\% of all words coded in English weekly forums compared to $17 \%$ in Chemistry). Both Chemistry and English were coded as having roughly the same amount of negative comments ( $6 \%$ and $7 \%$ respectively). Note that we also endeavored to distinguish attitude from types of writing critique. One could have a positive attitude while providing constructive critique for writing improvements, for example. The greater degree of positivity than negativity in the forums suggests that the forums can provide a meaningful mechanism for establishing a

9 This table includes data from three Chemistry weekly discussion forums (weeks 1, 4, and 7) and four English Composition weekly discussion forums (weeks, 1, 4, 7, and 12). The Chemistry course was not 12 weeks long.

${ }^{10}$ The sum of each column is $100 \%$, meaning that each cell refers to the percentage of overall words coded to all weekly forums sampled. 
learning community that has the potential to enhance students' learning gains and course experience.

\section{Affect and Emotion}

Affective and emotional factors are known to play a role in the success of any pedagogical practice (Gannon \& Davies, 2007). Research shows that affect impacts students' response to feedback on their writing (Zhang, 1995). Affect and emotions have also been shown to be particularly important in engagement in science-related activities, and this, in turn, has been suggested as a link to improving public science literacy (Lin, 2012; Falk, 2007). Since MOOCs may be considered a pathway to increasing public understanding of scientific information and development of broadbased efficacy in essential skills such as writing, we were interested in how affect and emotion emerged in the discussion forums.

Figure 2 shows the result of queries to identify the coded affects and emotions in combined data from both courses in the weekly forums (See Appendix A for a list of all affect/ emotion nodes).

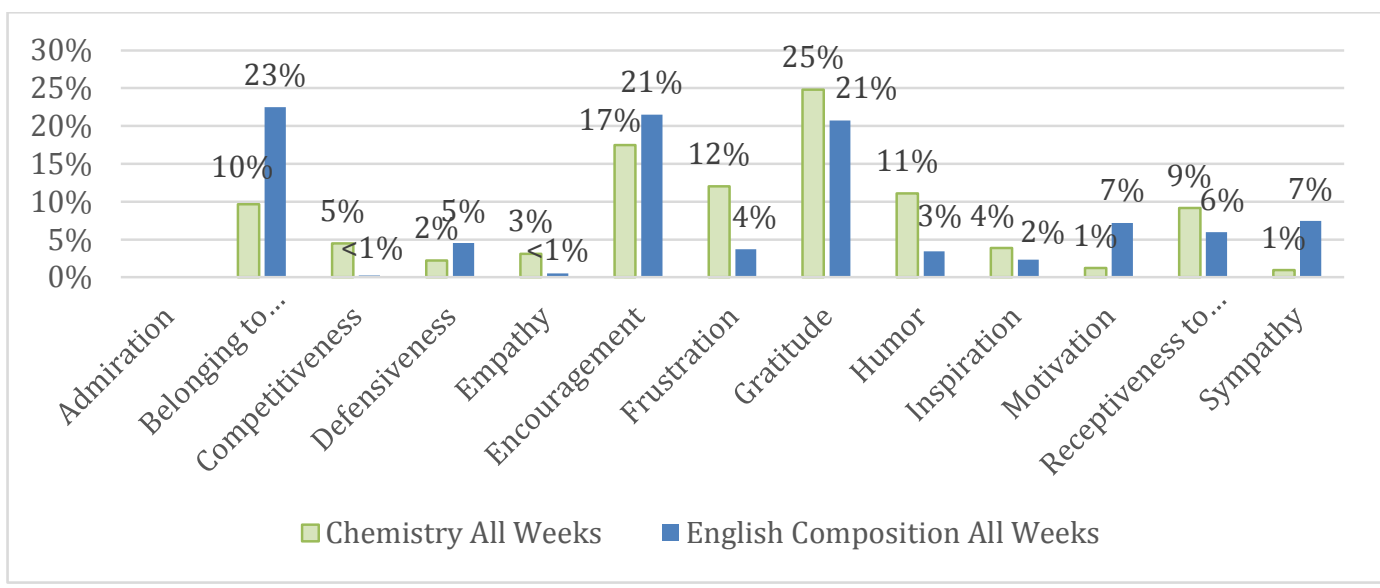

Figure 2. Percentages of posts coded to affects and emotions in weekly forums.

We coded to distinguish between attitude, as an evaluation, and affect, as an expression of feeling or emotion. Of course, students often expressed both an attitude and an affect, and in those cases, we coded to both types of nodes, but text was only coded to affect when appropriate. For example, the first quote below would be coded both to negative attitude and to the affect/ emotion of "frustration", whereas the second would be coded only to negative attitude.

Coded to both negative and frustration: “I haven't figured this one out either, or any other similar equation for that matter. I am getting really frustrated." 
Coded to negative, but not frustration: “I don't believe everyone watched and actually listened to the course instructor's direction on peer feedback. I doubt if anyone taking this course is a writing "Einstein" (genius)."

"Gratitude" and "encouragement" were in the top three of affects coded in discussion forum posts for both Chemistry and English Composition. Text coded to these affects ranged from simple phrases, such as "Thank you for your insights" or "I do think your efforts are praiseworthy," to lengthier:

“Do not give up! It can't always be easy. Believe me or not I do some review before the quizzes and I have not yet reached $100 \%$. Some of the questions are tricky! Try hard. Ask for help on the forums. You'll make it! :)"

In the English Composition course, "Belonging to community" was the most frequently coded affect. Text coded to this affect included the following types of posts:

"I believe most learners here are also not expert writers, just like you and me. So let's just keep writing and keep improving together, okay?"

"Most of the time, I feel like I'm an individual learner, but when I see the discussions, answers, and so on, I feel like there is someone who is doing something with me also, so I feel sometimes a group member."

"I'll hope we can interact, learn and share knowledge together."

In Chemistry, "frustration," "humor," and "belonging" were frequently coded affects:

"I am so confused about how to determine the protons and electrons that move and create different reactions. So frustrated."

"I got strange looks from people who don't think that a sleep-deprived working single mother should be giggling at chemistry at 2am."

"I've learnt so much from you all, and I know I can come with any question no matter how trivial."

While some writing was coded to "competitiveness" (for example, "I do not want to sound blatant or arrogant but I would expect it to be more challenging"), it was not a 
particularly prevalent affect. Rather, in both classes, students often expressed receptiveness to peer feedback or critique of their work.

"I hope someone will correct anything that is wrong about what I have just written."

"Oh right, I didn't notice it was in solid form when I answered! Thanks!”

"But the feedback from peers, critical, suggestive and appreciative, made it possible for me to improve upon my shortcomings and garner for myself scores of three 5's and a 5.5. Am I happy? I am indebted."

\section{Affect, Top Posters, and the General Discussion Forums}

In addition to the weekly forums which were set up by the course instructors, each course also contained other forums including one called "General Discussion." Table 7 compares the affect of top posters in each course to general discussion forum posters.

In Chemistry, the top posters most strongly expressed encouragement (23\% of the words coded to affect), a feeling of belonging to the community (21\%), and motivation (11\%). Comparatively, other posters in the Chemistry general discussion forum heavily expressed motivation (64\%), with the next most commonly expressed affect being gratitude (6\%). The top posters in Chemistry were also more frequently coded as being receptive to critiques (11\%) than the general posters (2\%).

Similarly, in English, the top posters in the general discussion forum were much more frequently coded as being receptive to critiques of their work by peers (29\%) than general posters (5\%). The top posters also much more frequently expressed defensiveness (20\%) than general forum posters (6\%). Posts in the forums most frequently were coding as expressing encouragement (20\%), belonging to the community (18\%), and gratitude (15\%). 
Table 7

Comparison of Affect among Top Posters in Each Course to Other Posters ${ }^{11}$

\begin{tabular}{|l|c|c|c|c|}
\hline \multicolumn{1}{|c|}{ Affect Nodes } & $\begin{array}{c}\text { Top posters } \\
\text { in } \\
\text { Chemistry }\end{array}$ & $\begin{array}{c}\text { Chemistry } \\
\text { forums }\end{array}$ & $\begin{array}{c}\text { Top posters in } \\
\text { English } \\
\text { Composition }\end{array}$ & $\begin{array}{c}\text { English } \\
\text { Composition } \\
\text { forums }\end{array}$ \\
\hline Admiration & $0 \%$ & $<1 \%$ & $0 \%$ & $<1 \%$ \\
\hline Belonging to community & $21 \%$ & $4 \%$ & $5 \%$ & $18 \%$ \\
\hline Competitiveness & $9 \%$ & $3 \%$ & $0 \%$ & $<1 \%$ \\
\hline Defensiveness & $5 \%$ & $1 \%$ & $20 \%$ & $6 \%$ \\
\hline Empathy & $0 \%$ & $1.87 \%$ & $0 \%$ & $2 \%$ \\
\hline Encouragement & $23 \%$ & $7 \%$ & $13 \%$ & $20 \%$ \\
\hline Frustration & $0 \%$ & $5 \%$ & $<1 \%$ & $9 \%$ \\
\hline Gratitude & $5 \%$ & $6 \%$ & $6 \%$ & $15 \%$ \\
\hline Humor & $3 \%$ & $4 \%$ & $3 \%$ & $2 \%$ \\
\hline Inspiration & $10 \%$ & $2 \%$ & $10 \%$ & $7 \%$ \\
\hline Motivation & $11 \%$ & $64 \%$ & $7 \%$ & $12 \%$ \\
\hline $\begin{array}{l}\text { Receptiveness to critique } \\
\text { or comment }\end{array}$ & $11 \%$ & $2 \%$ & $29 \%$ & $5 \%$ \\
\hline Sympathy & $3 \%$ & $<1 \%$ & $8 \%$ & $4 \%$ \\
\hline
\end{tabular}

\section{Learning Gains and Forum Posts}

One criticism of MOOCs is that assessment of student learning can be difficult when relying on multiple-choice quizzes (Meisenhelder, 2013). Many MOOCs, however, have much more versatile assignment types and answer formats available (Balfour, 2013; Breslow et al., 2013). Writing in MOOCs-whether through formal writing assignments, short-answer quizzes, or discussion-forum dialogue - can offer a strong opportunity for students to gain in learning objectives and for researchers to assess student learning (Comer, 2013). Some prior literature has even suggested that people can be more reflective when their engagement is via online writing than in face-to-face interaction (Hawkes, 2001).

Prior research reveals that through forum writing and peer assignment exchanges, students could be viewed as moving through phases of practical inquiry: triggering

${ }^{11}$ The discussion forums may include some of the posts written by top posters.

${ }^{12}$ The sum of each column is $100 \%$, meaning that each cell refers to the percentage of overall words coded to top posters.

${ }^{13}$ The sum of each column is $100 \%$, meaning that each cell refers to the percentage of overall words coded to forums. 
event, exploration, integration, and resolution (Garrison, Anderson, \& Archer, 2001). Discussion forums in particular offer a rich opportunity for examining student learning gains. Learning gains can be probed by analyzing student dialogue in the discussion forums to evaluate the nature and quality of the discourse. Through our coding of discussion forum posts, we were able to gain insights into student learning gains. Some students enthusiastically post about their learning experiences. Table 8 shows the percentage of discussion forum posts that demonstrated learning gains.

Table 8

Summary of Coding to Learning Gains in Discussion Forums by Course

\begin{tabular}{|l|l|l}
\hline Learning gains (aggregated) & Chemistry forums & English \\
\hline & $37.6 \%$ & $62.4 \%$
\end{tabular}

Some of these posts about learning gains are quite general in nature: "I don't know about you, but I've already learned an amazing amount from this class!"

Others show very discrete evolutions in learning:

"I was stuck with the idea that my introductions should be one paragraph long. Maybe I should experiment with longer introductions."

"And I feel comfortable enough with the chemistry, the basic chemistry, to not avert my eyes like I used to. Whenever I saw a chemical equation I just, oh well, never mind, and I'd just skip it."

Figure 3 shows the distribution of these learning gains in Chemistry forums. When learning gains were present in Chemistry discussion-forum posts, they were frequently coded to demonstrating understanding.

Figure 4 shows the distribution of these learning gains in English Composition discussion forums. When learning gains were present, they were most often related to demonstrating understanding, but also showed significant gains in evidence of incorporating feedback. Like the learning gains in Chemistry, English Composition students also had a very low incidence of discussions about their grades $(3.27 \%$ and $1.58 \%$, respectively).

\footnotetext{
${ }^{14}$ The sum of each row is $100 \%$, meaning that each cell refers to the percentage of overall words coded to a learning gains.
} 


\section{Learning Gains in Chemistry Discussion Forums}

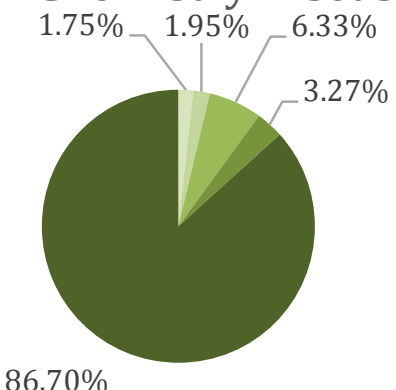

Learning Gains $\quad$ Demonstrates what has learned

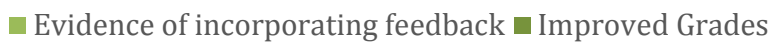

- Understanding

Figure 3. Coding to learning gains in Chemistry discussion forums.

\section{Learning Gains English Composition} Discussion Forums

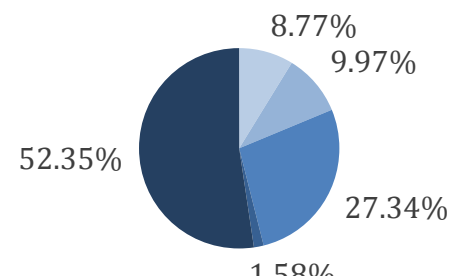

$1.58 \%$

— Learning Gains — Demonstrates what has learned

घvidence of incorporating feedback $\mathbf{~ I m p r o v e d ~ G r a d e s ~}$

-Understanding

Figure 4. Coding to learning gains in English Composition discussion forums.

In both courses, very little text was coded to the "improved grades" node. Research shows that a focus on grades can be counterproductive to learning gains (Kohn, 2011). The coding results here suggest, therefore, that when students were discussing learning gains they were discussing more meaningful measures of learning gains than grades. Indeed, students posting on the forums in these MOOCs were much more focused on learning than on grade outcomes. As an illustration, one student expressed this sentiment concisely by writing, "I am not hung up on the grade I am too excited about what I learned and how I am putting it into practice and getting results." 


\section{Writing Elements in Peer Review}

Enrollees' tendency to discuss more meaningful measures of learning gains in the forums also extended to their interactions through peer review. Peer review is more effective when peers focus on higher order writing elements as opposed to lower order concerns (Elbow, 1973; Clifford, 1981; Nystrand, 1984; Keh, 1990). Figure 5 shows the writing elements learners commented on in the open-ended peer review questions. For English Composition, learners commented most frequently on argument and analysis, format and style, and structure. For Chemistry, learners commented most frequently on topic, evidence and research, and plagiarism.

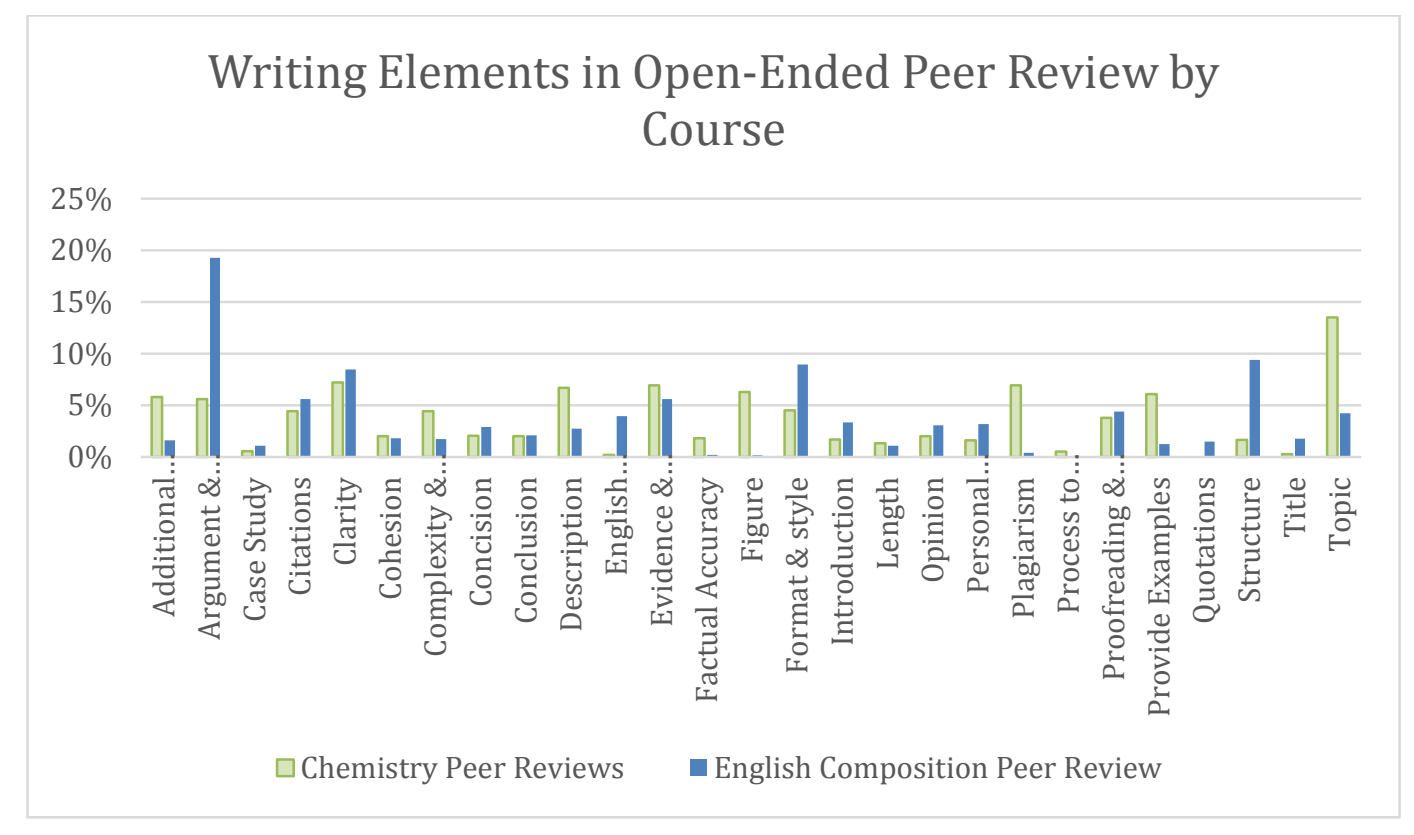

Figure 5. Writing elements in open-ended peer review by course.

The greater prevalence of peer notations about plagiarism in Chemistry is likely due to the course instructor specifically asking peers to look for plagiarism: "This is going to come up some small fraction of the time, so here is the procedure: What should you do if you are reviewing an essay that you believe is blatant plagiarism?" Suspected plagiarism was then confirmed by the instructor, who investigated student flagged work. Editorials have expressed concern that MOOC providers and faculty need to be more rigorous at facilitating academic integrity and discouraging or penalizing plagiarism (Young, 2012). Continued work should indeed be done in this area. This is especially important given that, when writing assignments are used on this scale, observations made in face-to-face settings can be magnified. For example, Wilson noted in the summary of his work about writing assignments in a face-to-face chemistry course that "Not all students submitted original work" (Wilson, 1994, p. 1019). A perusal of 
Chronicle of Higher Education faculty forums reveals that plagiarism continues to constitute a challenge in all educational settings rather than being unique to MOOCs.

However, while academic honesty is of the utmost importance, it is also important to continue facilitating peer commentary based on other elements of writing, especially the higher order concerns named above. Some students expressed a negative impact from what they perceived to be too great a focus by their peers on plagiarism in the Chemistry peer review: "This peer review exercise is rapidly turning into a witch hunt. My opinion of this course has, during the past 2 days, gone from wildly positive to slightly negative."

\section{Type of Feedback in Peer Review}

Research shows the kind of peer feedback provided impacts peers' perceptions of the helpfulness of that feedback (Cho, Schunn, \& Charney, 2006). We categorized peer feedback by type: positive, constructive, or negative. We defined positive as consisting of compliments that were not related to improving the paper; constructive comments included helpful feedback that a writer could use to improve his or her project or take into consideration for future writing occasions; and negative feedback included comments that were not compliments and were also unconstructive/unhelpful. The ratios of feedback coded as compliment:constructive:negative/unconstructive was 56:42:2 in the peer reviewed assignments and 8:90:2 in the weekly and general discussion forums.

Below are examples of text coded as unconstructive and constructive, respectively:

"Did not read past the $3^{\text {rd }}$ paragraph ... I am sure it was interesting . . . You just did not keep my interest."

"Below are my suggestions as a Anglophone and an opinionated reader. ...... Before we begin, you used the word feedbacks in the title of this thread. Feedback is the correct term. One of those annoying inconsistencies in English."

\section{Positive feedback in peer review.}

Figure 6 shows the distribution of writing elements specifically among positive feedback in the peer review process, what we termed "compliments." For Chemistry, compliments were most often focused on topic, clarity, description, evidence and research, and figure (learners included figures in their chemistry assignments). For English Composition, positive feedback was most often focused on argument and analysis, structure, format, and topic. Compliments were least often provided in Chemistry peer reviews to the 
process of assigning peer review, proofreading and grammar, and quotations. ${ }^{15}$ Positive feedback was least often provided in English Composition peer reviews to process of assigning peer review, factual accuracy, and figure.

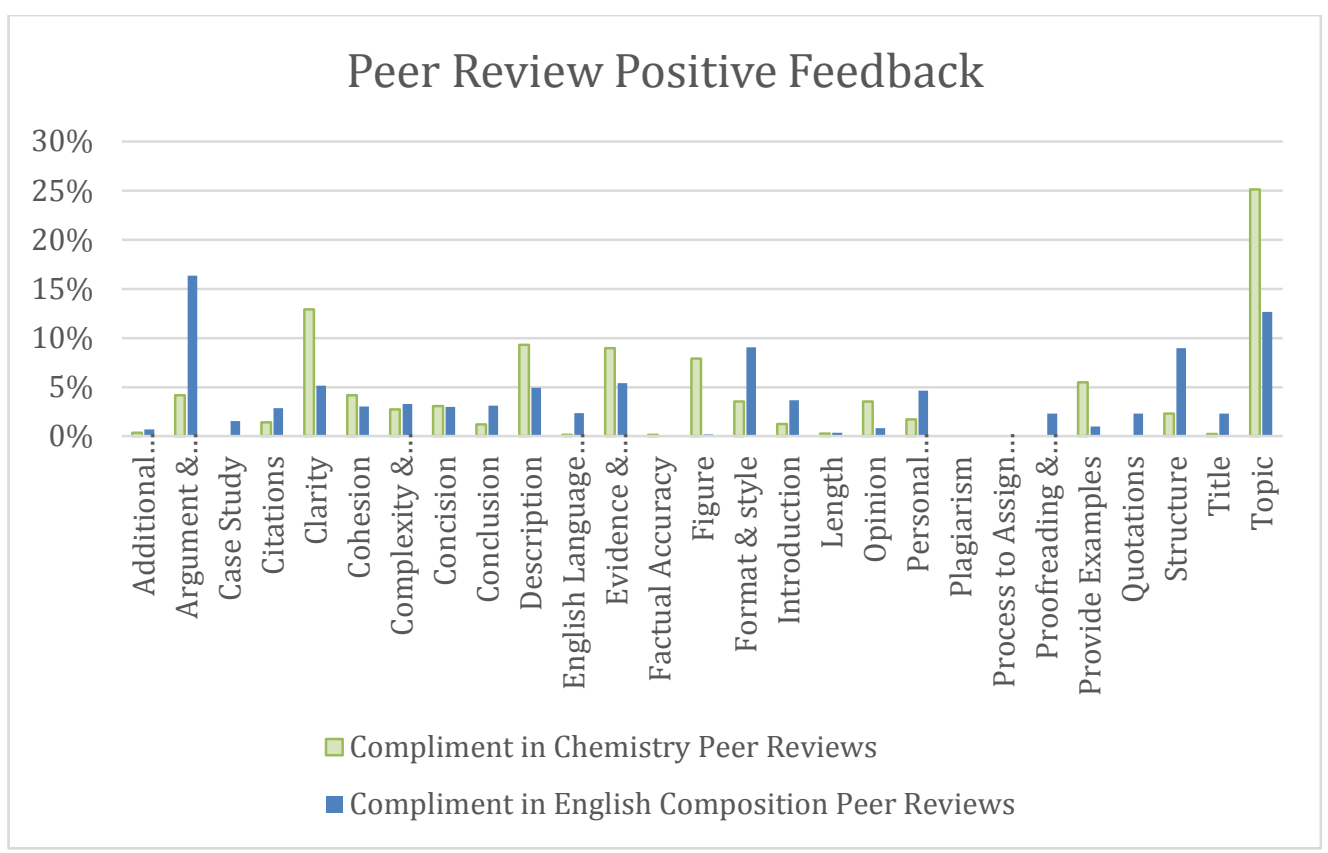

Figure 6. Positive feedback writing elements in peer review open ended questions by course $^{16}$.

Students posted positive feedback illustrated by the following excerpts:

"Well written. Good explanations of the chemistry. I liked how it was a topic that you are clearly passionate about."

"I liked your essay, it is cohesive and concise and its subject is intriguing!"

"You did the great research ... and your bibliography is impressive. The introduction is brief, but sufficient, the problem you've built your text on is claimed clearly, and

${ }^{15}$ Compliments were also least often coded to plagiarism in both courses, but we eliminated that from the compliments because noting plagiarism is implicitly not considered a compliment. The writing element labeled Citations enables learners to comment on citation in the form of a compliment.

${ }^{16}$ Total distribution for each course is $100 \%$, meaning that each percentage refers to the percentage of overall words coded to the positive feedback (or compliment) node for a given course. 
your arguments are well supported by references and quotations."

\section{Constructive criticism in peer feedback.}

Peers in English Composition were most likely to provide constructive feedback on argument and analysis, English language skills, citations, and format and style. Peers in Chemistry were most likely to provide constructive criticism on additional resources, topic, format and style, and factual accuracy. Coding frequency for both courses is shown in Figure 7.

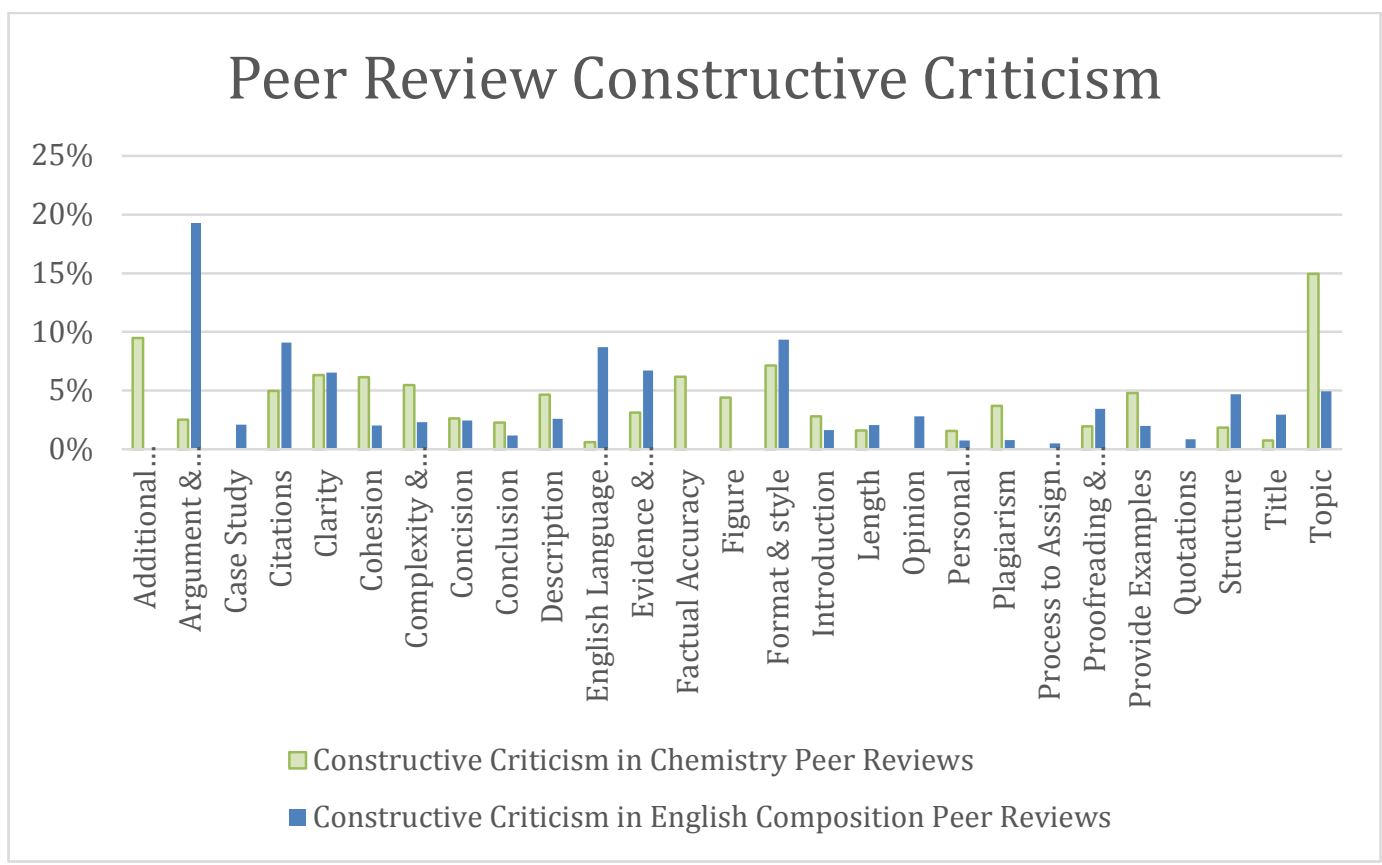

Figure 7. Constructive criticism writing elements in peer review open ended questions by course. ${ }^{17}$

Students posted constructive criticism such as the following:

“... I could hear your voice among the voices of the cited books and articles, but it is not always obvious where you agree and where you oppose to the cited claim. Probably, you could sharpen your view and make your claim more obvious for your readers."

${ }^{17}$ Total distribution for each course is $100 \%$, meaning that each percentage refers to the percentage of overall words coded to the constructive feedback node for a given course. 
"J ust as a tip, you could have shown some pictures" of the funghi.

\section{Unconstructive criticism in peer review.}

Unconstructive feedback was defined as comments that were negative but not helpful in terms of recommending specific improvements to the student whose work was being reviewed. Figure 8 shows the distribution of unconstructive feedback in the open-ended peer reviews in each course. Peers were most likely to center unconstructive feedback in English Composition on matters of argument and analysis, clarity, and format and style. For Chemistry, peers were most likely to provide unconstructive feedback on topic, opinion, and additional resources.

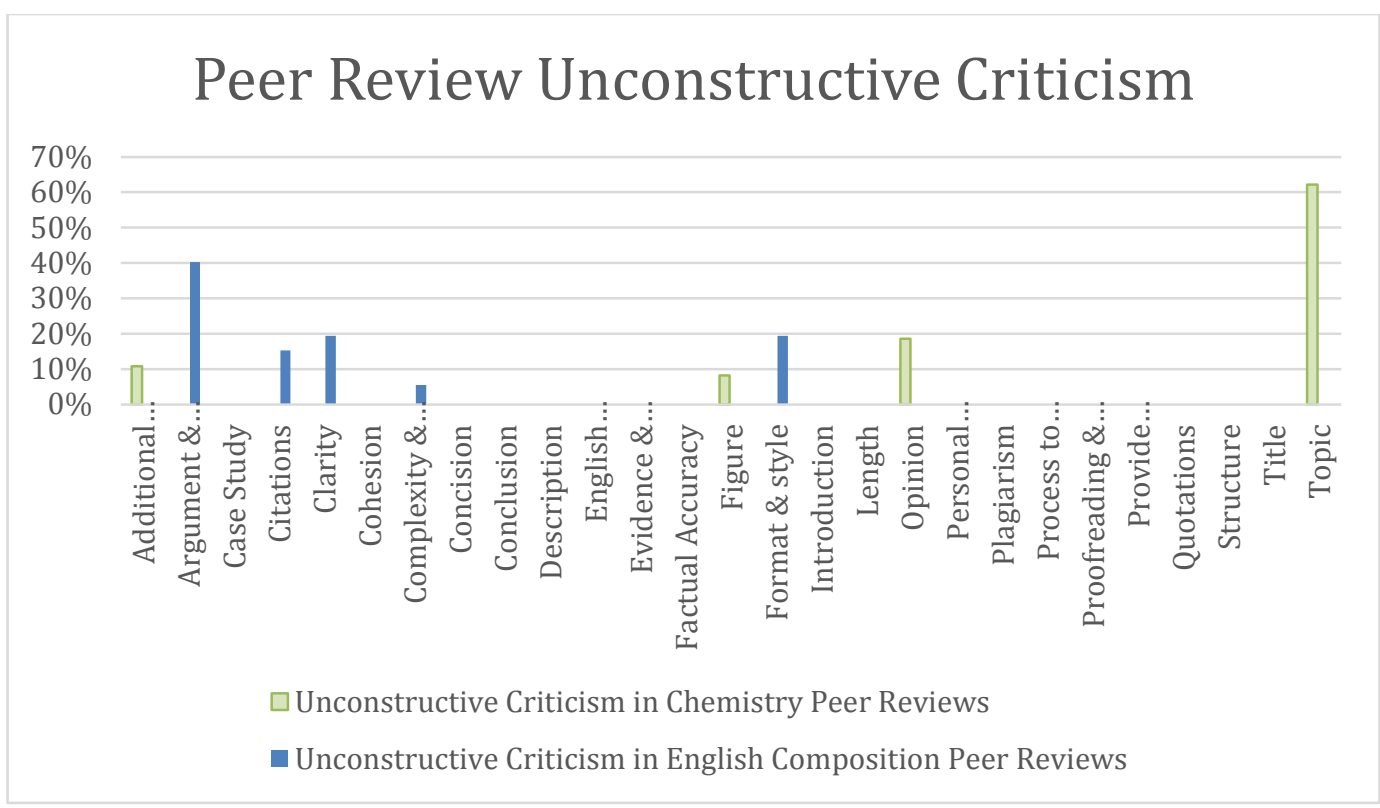

Figure 8. Unconstructive criticism writing elements in peer review open ended questions by course. 18

Examples of unconstructive feedback included the following: "Did not read past the $3^{\text {rd }}$ paragraph ... I am sure it was interesting .. . You just did not keep my interest."

It is important to note that because we did not code the assignment submissions themselves, it may have sometimes been difficult to identify what is or is not constructive or unconstructive feedback, particularly in the case of citations and plagiarism. For instance, in some cases, peers responded to feedback as though it were

${ }^{18}$ Total distribution for each course is $100 \%$, meaning that each percentage refers to the percentage of overall words coded to the unconstructive feedback node for a given course. 
unconstructive, but we do not know for sure whether this feedback about citations was or was not warranted:

"I did research and re-phrased parts of my sources into this essay with citations as is accepted practice. Did you expect me to carry out my very own experiments and post the results? I mean honestly, I am offended by that suggestion. ... The only issue I can see is that the numbering of the citations went off during editing, but since all of my sources are still listed at the bottom of the essay this should not be a problem ... It is also my work, so I would like you to retract your statement, I find it offensive."

\section{Learning Gains and Peer Feedback}

Peer feedback has been shown to enhance learning environments (Topping, 1998). Many posts in the discussion forums and peer reviews from both courses, as well as in the final reflective essays from English Composition learners, indicate that the peerfeedback process contributed to their learning gains. ${ }^{19}$ Some of these posts about learning gains from the peer-feedback process are general in nature:

"I found peer comments and their assessment invaluable."

"[I have been] learning so much from all of the peer review submissions that I have decided to remain in the course just to learn everything I can learn about Chemistry."

"Throughout the course, I valued my peer's comments on my drafts so I can improve my writings. I also learnt much by evaluating my peers' work."

Other posts show very discrete evolutions in learning:

"I am, however, grateful for the kind parts of your review, and willingly admit to faults within the essay, although until this week, I was, like my fellows, unaware of the expected work on electron transits. By the time I did become aware of this, it was too late to make alterations! Thank you for a thoughtful review."

${ }^{19}$ Assignments and peer-feedback rubrics for English Composition were designed in collaboration with writing assessment expert Edward M. White. 
"Even more important bit I learned was the importance of feedback. Feedback provides an opportunity to rethink the project, and dramatically improve it."

Table 9 shows the frequency of when peer feedback explicitly expressed learning gains. The English Composition peer review rubric specifically asked reviewers to indicate what they had learned from reading and responding to the peer-writing project (see Appendix F). The Introduction to Chemistry peer rubric did not ask this. This probably accounts for why the learning gains were so much more evident in peer review in English Composition than in Chemistry.

Table 9

Learning Gains in Peer Review

\begin{tabular}{|l|l|l|}
\hline & Chemistry peer review & English peer review \\
\hline Learning gains $^{20}$ & $2.55 \%$ & $97.45 \%$ \\
\hline
\end{tabular}

Figure 9 shows coding for specific learning gains in peer feedback. In English Composition, peer review provided students with learning gains across four primary areas: understanding, learning through providing peer feedback, demonstrating what the person had learned, and evidence of incorporating feedback. In Chemistry, learning gains from peer feedback occurred most often around matters of understanding, demonstrating what the person had learned, and evidence of incorporating feedback. As with the learning gains in discussion forum posts, the coding shows that students are not focusing on grades, but are instead focusing on higher order concerns.

${ }^{20}$ The sum of each row is $100 \%$, meaning that each cell refers to the percentage of overall words coded to a learning gains. 


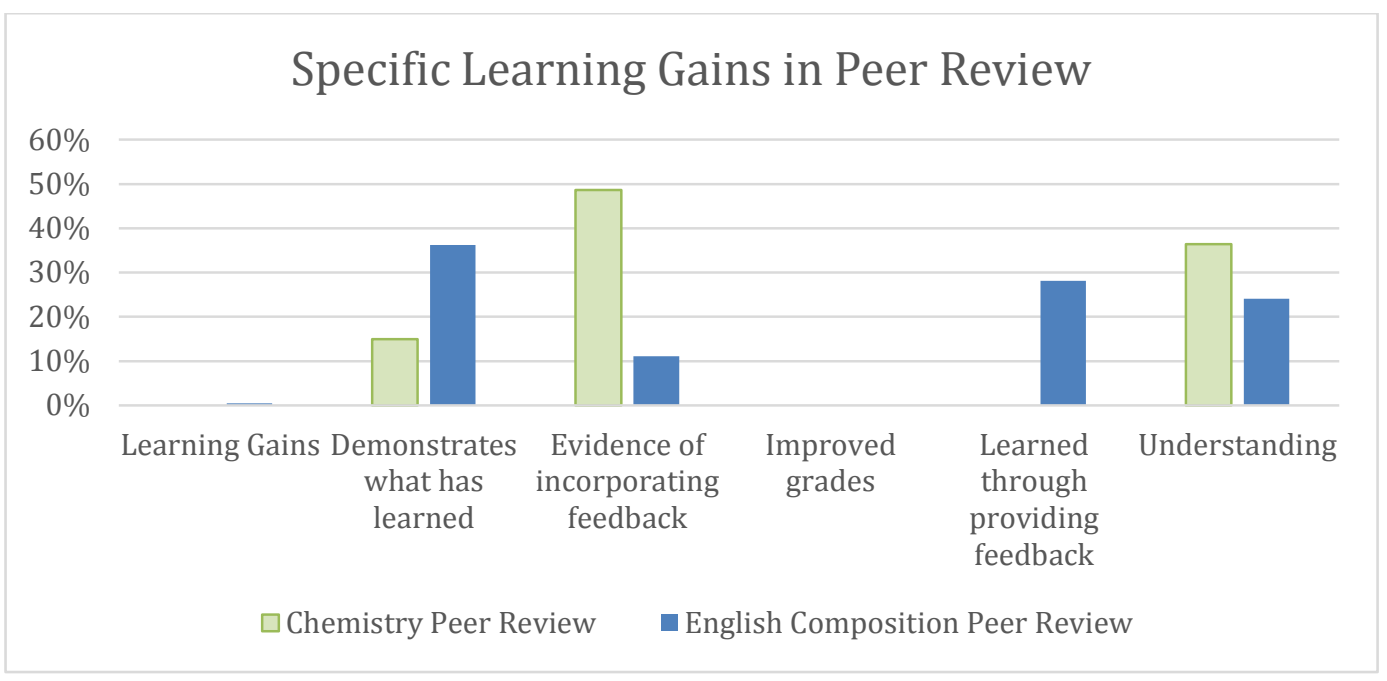

Figure 9. Specific learning gains in peer review.

\section{Learning Gains and Student Challenges}

Because we are interested in the impact of peer-to-peer interactions with less academically prepared students, we specifically looked for challenges faced by students, such as the following: lack of time or energy; ${ }^{21}$ less academically prepared; and less or not self-directed. Interestingly, little text was coded to these nodes. For example, only one coding reference was found at the intersection of any of these challenges and learning gains. Therefore, these barriers did not come up in the forum threads that we coded in either class.

\section{Discussion/Conclusions}

We have identified several significant themes that show the importance of and impact of the peer-to-peer interaction through writing in MOOCs.

\section{MOOC Discussion Forum Posts are Connected to Course Content}

Both courses examined generated substantial student dialogues on the forums. Students in the English Composition: Achieving Expertise course tended to write longer forum posts than students in the Introduction to Chemistry course. Peer-to-peer dialogue on the weekly forums closely mirrored the content of the course described in the syllabus for that week. This shows that students are primarily discussing course content in these

${ }^{21}$ Lack of time or energy could be a factor associated with less academically prepared students, or it could be unconnected to that mode of student challenge. 
forums and suggests that peer-to-peer writing in the forums can provide one measure of student success in a MOOC.

\section{MOOC Discussion Forums Generally Contribute Positively to the Learning Environment in Chemistry and English Composition}

Since attitude was generally positive and the top affects in the forums include belonging to a community, gratitude, and encouragement, we conclude that the forums are in general a positive space for learners to interact. This finding operated across disciplinary context, both in a natural science course and in a more humanities oriented course.

\section{MOOC Discussion Forums Contribute to Learning Gains, Especially in Understanding}

In terms of observed learning gains, peer-to-peer interaction on the forums seemed to make the most impact on enhancing and facilitating understanding. Students sought, offered, and provided tips or support from one another on the forums as a way of increasing their understanding of course content.

\section{Peer Review Can Facilitate Learning Gains If This Possibility is Made Explicit}

The disparity between the coding for learning gains in English peer reviews and in Chemistry peer reviews suggests that the English students were indicating learning gains because they were asked to do so explicitly. This suggests that faculty should encourage students to reflect on their learning gains explicitly as a way of facilitating those very learning gains.

\section{Peer Feedback on Writing can Meaningfully Focus on Higher Order Concerns across Disciplines}

Feedback on writing can be differentiated between that which focuses on higher order or lower order concerns. Effective formative feedback generally must include a focus on higher order concerns, and can then be considered an integral part of the learning and assessment environment (Gikandi, 2011). Peers in both courses focused predominately on higher order concerns, even as they were also able to focus on lower order concerns. This may be due to the peer feedback rubrics. Our data also suggest that peers will follow closely the rubric provided by the instructor. In English Composition, students were asked to focus on argument and analysis. In Chemistry, students were asked to focus on strengths, insights, areas for improvements, and plagiarism. In both cases the students were likely to adhere to the rubric guidelines. 


\section{Writing through the Forums Enhances Understanding}

Since forum discussions in a MOOC happen through writing, one can extrapolate from our data that writing enhances understanding in MOOC forums. This bolsters evidence for writing-to-learn and suggests that MOOC forums are a key pathway for writing-tolearn and a key pathway for assessing student success in MOOCs across disciplines.

\section{A Limited Group of Learners Posts to the Forums}

One of our key areas of inquiry was to understand how peer-to-peer interaction through writing might impact the learning gains of less academically prepared learners. We found, however, that people posting to the forums did not identify themselves explicitly as less academically prepared. This generates questions about how many people post to the forums, and who is or is not likely to post to the forums. The total number of people who posted to the discussion forums in English Composition represents $23 \%$ of the total number of people who ever actually accessed the course (51,601); in Chemistry, the total number of people who posted to the discussion forums represents $7 \%$ of the total number of people who ever actually accessed the course $(22,298) .22$ Given the overall positivity of the forums, one wonders if these data indicate that the forums are only positive for certain types of people. Given that the top posters coded higher for "defensiveness" than general posters, one also wonders if there might be drawbacks to certain levels of forum participation. We did not see any significant information about student challenges in the coding data, despite looking for it as one of our coding nodes. Since interactive learning offers so much promise for these learners, and since MOOCs continue to provide the possibility of increased access to higher education, more research is needed about how to facilitate forums in as inclusive and productive a way as possible for less academically prepared learners.

The development of quality educational opportunities through MOOCs, and learning more about how peer interactions through writing contribute to student retention and learning, has the potential to make a significant global impact and increase postsecondary access and success in unprecedented ways. As we discover more through this research about how peer interactions with writing contribute to student learning outcomes and retention, we will be better positioned to understand and work towards a model of higher education that is more flexible, accessible, and effective for the great many individuals in the world interested in pursuing lifelong learning.

${ }^{22}$ Coursera also counts the number of people who comment on the forums, so the percentage might be a little higher for forum participation if we included this number. However, the people who comment may also be the people who post, and so counting it this way could have ended up in duplicating data. 


\section{Acknowledgements}

We would like to acknowledge the work of the coding team: Michael Barger, Dorian Canelas, Beatrice Capestany, Denise Comer, Madeleine George, David Font-Navarette, Victoria Lee, J ay Summach, and Mark Ulett. Charlotte Clark led the coding workshop with the assistance and data analysis of Noelle Wyman Roth. The figures included in this article were developed by Noelle Wyman Roth. We appreciate the generous funding of this work that was received from several sources. Dorian Canelas and Denise Comer were successful applicants of a competitive grant competition run by Athabasca University (Principal Investigator: George Siemens). This project, the MOOC Research Initiative, was designed to advance understanding of the role of MOOCs in the education sector and how emerging models of learning will influence traditional education. The MOOC Research Initiative is a project funded by the Bill \& Melinda Gates Foundation. This research was also funded through matching funds from the office of the Provost at Duke University. Denise Comer's course was funded largely by a grant from the Bill \& Melinda Gates Foundation. We are grateful that development of both courses received support from the talented technology staff and instructional teams in Duke University's Center for Instructional Technology. Research in Dorian Canelas's course was also supported by funding from the Bass Connections program. We appreciate the support and encouragement of Keith Whitfield. We acknowledge that a portion of the work described herein was conducted under the guidelines set forth in Duke University IRB Protocol B0596 (Student Writing in MOOC). 


\section{References}

Adamopoulos, P. (2013). What makes a great MOOC? An interdisciplinary analysis of student retention in online courses. Thirty fourth international conference on Information Systems, Milan.

Armstrong, D., Gosling, A., Weinman, J ., \& Marteau, T. (1997). The place of inter-rater reliability in qualitative research: An empirical study. Sociology, 31(3), 597-606.

Balfour, S. P. (2013). Assessing writing in MOOCs: Automated essay scoring and calibrated peer review. Research \& Practice in Assessment, 8(1), 40-48.

Bernard, R. M., Abrami, P. C., Lou, Y., Borokhovski, E., Wade, A., Wozney, L., ... \& Huang, B. (2004). How does distance education compare with classroom instruction? A meta-analysis of the empirical literature. Review of Educational Research, 74(3), 379-439.

Boynton, L. (2002). When the class bell stops ringing: The achievements and challenges of teaching online first-year composition. Teaching English in the Two-Year College, 29(3), 298-311.

Breslow, L., Pritchard, D. E., DeBoer, J., Stump, G. S., Ho, A. D., \& Seaton, D. T. (2013). Studying learning in the worldwide classroom: Research into edx's first mooc. Research \& Practice in Assessment, 8, 13-25.

Brinton, C. G., Chiang, M., J ain, S., Lam, H., Liu, Z., \&Wong, F. M. F. (2013). Learning about social learning in MOOCs: From statistical analysis to generative model. arXiv preprint arXiv: 1312.2159.

Cain, J ., Conway, J ., DiVall, M., Erstad, B., Lockman, P., Ressler, J ., ... Nemire, R. (2014). Report of the 2013-2014 academic affairs committee. American Association of Colleges of Pharmacy. Alexandria, VA: Cain.

Carter, M. (2007). Ways of knowing, doing, and writing in the disciplines. College Composition and Communication, 385-418.

Chi, M. T. (2009). Active-constructive-interactive: A conceptual framework for differentiating learning activities. Topics in Cognitive Science, 1(1), 73-105.

Cho, K., Schunn, C. D., \& Charney, D. (2006). Commenting on writing typology and perceived helpfulness of comments from novice peer reviewers and subject matter experts. Written Communication, 23(3), 260-294.

Clarà, M., \& Barberà, E. (2013). Learning online: Massive open online courses (MOOCs), connectivism, and cultural psychology. Distance Education, 34(1), 129-136. 
Clifford, J . (1981). Composing in stages: Effects of feedback on revision. Research in the Teaching of English, IS, 37-53.

Comer, D. (2013) “MOOCs offer students opportunity to grow as writers." iiis.org.

Cooper, M. (1993). "Writing: An approach for large-enrollment chemistry courses." J ournal of Chemical Education, 70(6), 476-477.

Crews, D. M., \& Aragon, S. R. (2004). Influence of a community college developmental education writing course on academic performance. Community College Review, 32(2), 1-18.

Crosling, G., Thomas, L., \& Heagney, M. (2008). Improving student retention in higher education: The role of teaching and learning. Routledge.

Daempfle, P. A. (2004). An analysis of the high attrition rates among first year college science, math, and engineering majors. J ournal of College Student Retention, 5, 37-52.

Denzin, N.K. (2009). The research act: A theoretical introduction to sociological methods. New York: McGraw-Hill.

deWaard, I., Abajian, S., Gallagher, M. S., Hogue, R., Keskin, N., Koutropoulos, A., Rodriguez, O. C. (2011). Using mLearning and MOOCs to understand chaos, emergence, and complexity in education. The International Review of Research in Open and Distance Learning, 12(7), 94-115. Retrieved from http:/ / www.irrodl.org/index.php/irrodl/article/view/ 1046/2026

Elbow, P. (1973). Writing without teachers. London: Oxford University Press.

Emanuel, E. J . (2013). Online education: MOOCs taken by educated few. Nature, 503(7476), 342-342.

Falk, J . H., Storksdieck, M., \&Dierking, L. D. (2007). Investigating public science interest and understanding: Evidence for the importance of free-choice learning. Public Understanding of Science, 16(4), 455-469.

Gannon, S., \& Davies, C. (2007). For love of the word: English teaching, affect and writing 1. Changing English, 14(1), 87-98.

Garrison, D. R., Anderson, T., \& Archer, W. (2001). Critical thinking, cognitive presence, and computer conferencing in distance education. American J ournal of Distance Education, 15(1), 7-23. 
Gikandi, J. W., Morrow, D., \& Davis, N. E. (2011). Online formative assessment in higher education: A review of the literature. Computers \& Education, 57(4), 2333-2351.

Guo, P. J ., \& Reinecke, K. (2014, March). Demographic differences in how students navigate through MOOCs. In Proceedings of the first ACM conference on Learning@ scale conference (pp. 21-30). ACM.

Hawkes, M. (2001). Variables of interest in exploring the reflective outcomes of network-based communication. J ournal of Research on Computing in Education, 33(3), 299-315.

Huang, H. M. (2002). Toward constructivism for adult learners in online learning environments. British J ournal of Educational Technology, 33(1), 27-37.

J ohnson, D. W. (1981). Student-student interaction: The neglected variable in education. Educational Researcher, 5-10.

J oyner, F. (2012). Increasing student interaction and the development of critical thinking in asynchronous threaded discussions. J ournal of Teaching and Learning with Technology, 1(1), 35-41.

Keh, C. L. (1990). Feedback in the writing process: A model and methods for implementation. ELT journal, 44(4), 294-304.

J . Kim, in Inside Higher Educ.

(2012), http:// www.insidehighered.com/ blogs/ technologyandlearning/ playing-role-mooc-skeptic-7-concerns

Kohn, A. (2011). The case against grades. Educational Leadership, 69(3), 28-33.

S. Kolowich, in Inside Higher Ed. (2011), http:// www.insidehighered.com/news/2011/04/07/gates foundation announces higher education technology grant_winners

Kop, R., Fournier, H., \&Mak, J . S. F. (2011). A pedagogy of abundance or a pedagogy to support human beings? Participant support on massive open online courses. International Review of Research in Open and Distance Learning, 12(7), 74-93.

Kuh, G. D. (2008). Excerpt from "High-impact educational practices: What they are, who has access to them, and why they matter". Association of American Colleges and Universities. 
Lin, H.-S., Hong, Z.-R., \& Huang, T.-C. (2012). The role of emotional factors in building public scientific literacy and engagement with science. International J ournal of Science Education, 34(1), 25-42.

Mammino, L. (2011). Teaching chemistry in a historically disadvantaged context: experiences, challenges, and inferences. J ournal of Chemical Education, 88(11), 1451-1453.

Maxwell, J .A. (2005). Qualitative research design: An interactive approach. 2nd eduction. Sage. Thousand Oaks, CA.

Meisenhelder, S. (2013). MOOC mania. Thought and Action, 7.

Nystrand, M. (1984). Learning to write by talking about writing: A summary of research on intensive peer review in expository writing instruction at the University of Wisconsin-Madison. National Institute of Education (ED Publication No. ED 255 914). Washington, DC: U.S.-Government Printing Office. Retrieved from http:// files.eric.ed.gov/fulltext/ ED255914.pdf

Pelaez, N. J . (2002). Problem-based writing with peer review improves academic performance in physiology. Advances in Physiology Education, 26(3), 174-184.

Pienta, N. J . (2013). Online courses in chemistry: salvation or downfall? J ournal of Chemical Education, 90(3), 271-272.

Pomerantz, J . (2013). Data about the Metadata MOOC, Part 3: Discussion Forums. J effreypomerantz.name.

Reynolds, J . A., Thaiss, C., Katkin, W., Thompson, Jr. R. J . (2012). Writing to learn in undergraduate science education: A conceptually driven approach. CBE Life Science Education, 11(1), 17-25.

Rivard, L. P., \& Straw, S. B. (2000). The effect of talk and writing on learning science: An exploratory study. Science Education, 84(5), 566-593.

Ruey, S. (2010). A case study of constructivist instructional strategies for adult online learning. British J ournal of Educational Technology, 41(5), 706-720.

Salomon, G., \&Perkins, D. N. (1998). Individual and social aspects of learning. Review of Research in Education, 1-24.

Siemens, G. (2005). Connectivism: A learning theory for the digital age. International J ournal of Instructional Technology and Distance Learning, 2(1), 3-10.

Sorcinelli, M. D., \& Elbow, P. (1997). Writing to learn: Strategies for assigning and responding to writing across the disciplines. J ossey-Bass. 
Topping, K., \& Ehly, S. (Eds.). (1998). Peer-assisted learning. Routledge.

Vàzquez, A. V., McLoughlin, K., Sabbagh, M., Runkle, A. C., Simon, J., Coppola, B. P., Pazicni, S. (2012). Writing-to-teach: A new pedagogical approach to elicit explanative writing from undergraduate chemistry students. J ournal of Chemical Education, 89(8), 1025-1031.

Waldrop, M. (2013). Campus 2.0: Massive open online courses are transforming higher education and providing fodder for scientific research. Nature, 495, 160 (March 14, 2013).

Watkins, J ., \& Mazur, E. (2013). Retaining Students in science, technology, engineering, and mathematics (STEM) majors. J ournal of College Science Teaching, 42(5).

Wilson, J oseph W., (1994). Writing to learn in an organic chemistry course. J ournal of Chemical Education, 71(12), 1019-1020.

Yang, Y. F., \& Tsai, C. C. (2010). Conceptions of and approaches to learning through online peer assessment. Learning and Instruction, 20(1), 72-83.

Young, J . L. (2012). Dozens of plagiarism incidents are reported in Coursera's free online courses. The Chronical of Higher Education. (August 16, 2012.) Retrieved from http:// chronicle.com/ article/ Dozens-of-PlagiarismIncidents/133697/

Yuan, L., \& Powell, S. (2013). MOOCs and open education: Implications for higher education. Cetis White Paper.

Zhang, S. (1995). Reexamining the affective advantage of peer feedback in the esl writing class. J ournal of Second Language Writing, 4(3), 209-222. 


\section{Apppendix A}

\section{Coding Protocol, Definitions, and Node Structure}

The following information helps define our terms: Forum: A forum is the top level discussion holder (Week 1). These are created in Coursera by instructional team staff. Subforum: A subforum is a discussion holder that fall under the top forum (Week 1 Lectures, Week 1 Assignment). These are also created by instructional team staff. Thread: A thread is a conversation begun by either instructional team staff or by students. A single forum typically contains many threads covering many different subjects, theoretically related to the forum's overarching topic. Post: A post is an individual's response to a thread. Posts can be made by either instructional team staff or by students, and may be posted with the students identifying name, or may be posted as anonymous. Staff with administrative privileges may "toggle" a setting on each post to reveal the identity of students who have chosen to post anonymously. Although in theory a post is a new "top level" contribution to an existing thread (as opposed to comment (read below), many students don't pay attention to whether they are posting or commenting, and therefore, we didn't feel that we could accurately distinguish between the two. Comment: A comment is a reply to a post. Comments can be made by either instructional team staff or by students. Again, we decided not to distinguish semantically between a post and a comment, because we felt that distinguishing them was not possible in (the very common) complex web of post, response, subsequent post, subsequent response, etc.

The main page of a forum lists all the primary threads begun in that forum or subforum. If threads are begun in a subforum, they are only listed in the "all threads" area of the subforum, not in the "all threads" list of any parent forum. Subforums may themselves have subforums (which are also called subforums). At the bottom of a list of "all threads," you can read the total number of pages of threads that exist; each page contains 25 thread headings. Therefore, an estimate of the number of threads can be obtained by multiplying the number of pages by 25 .

Coursera provides a number of views received by each thread, as well as the number of times a thread has been opened and read. Of course, by opening a thread to capture it for analysis, we are increasing the number of views of that thread, so we used the "views" number in our analysis with this limitation in mind.

Coursera also allows the viewer to sort by "Top Thread," "Most Recently Created," and "Most Recently Modified." We always sorted by "Top Thread" before beginning our sampling and capturing process. Top threads are defined as those that have the most posts and comments, views, and/or most reputation points or up votes on the original post that started the thread (see below). Number of posts, comments, and views 
certainly provide one measure of student engagement and activity. Two other related metrics exist in Coursera. Students can choose to vote certain posts "up" or "down," and are encouraged to do so to bring thoughtful or helpful posts to the attention of their peers. This simple "like" type of toggle exists at the bottom of each post or comment. Students also receive "reputation points" when their posts are voted up (or down) in the forums by other students. Specifically, "Students obtain reputation points when their posts are voted up (or down) in the forums by other students. For each student, his/ her reputation is the sum of the square-root of the number of votes for each post/comment that he/ she has made" (Pomerantz, 2013). Top posters are the students with the highest number of reputation points.

\section{Node Names and Coding Reference Quantity}

\begin{tabular}{|c|c|c|}
\hline Node Name & Sources23 & References24 \\
\hline Affect (aggregated) & 565 & 3103 \\
\hline Admiration & 89 & 104 \\
\hline Belonging to this community & 110 & 302 \\
\hline Competiveness & 20 & 44 \\
\hline Defensiveness & 27 & 71 \\
\hline Empathy & 49 & 77 \\
\hline Encouragement & 307 & 616 \\
\hline Frustration & 58 & 126 \\
\hline Gratitude & 243 & 510 \\
\hline Humor & 32 & 76 \\
\hline Inspiration & 52 & 78 \\
\hline Motivation & 57 & 766 \\
\hline $\begin{array}{l}\text { Receptiveness to critique or } \\
\text { comment }\end{array}$ & 176 & 256 \\
\hline Sympathy & 35 & 77 \\
\hline Attitude & 0 & 0 \\
\hline Negative & 131 & 296 \\
\hline Neutral & 382 & 1877 \\
\hline Positive & 507 & 1735 \\
\hline Feedback & 0 & 0 \\
\hline Compliment & 310 & 623 \\
\hline Constructive criticism & 174 & 310 \\
\hline Unconstructive criticism & 20 & 26 \\
\hline Learning through P2P writing & 94 & 105 \\
\hline Learning gains & 382 & 751 \\
\hline $\begin{array}{l}\text { Demonstrates what learned } \\
\text { (peer review) }\end{array}$ & 123 & 168 \\
\hline $\begin{array}{l}\text { Evidence of incorporating } \\
\text { feedback }\end{array}$ & 50 & 63 \\
\hline Improved grades & 4 & 5 \\
\hline $\begin{array}{l}\text { Learned through providing } \\
\text { feedback }\end{array}$ & 257 & 261 \\
\hline
\end{tabular}

\footnotetext{
${ }^{23}$ Sources is the number of documents that contain coding to a given node.

${ }^{24}$ References is the number of times an area of text was coded to that node.
} 


\begin{tabular}{|c|c|c|}
\hline Understanding & 143 & 225 \\
\hline Miscommunication & 3 & 9 \\
\hline Writing Elements & 0 & 0 \\
\hline Additional resources & 48 & 59 \\
\hline Argument and analysis & 163 & 228 \\
\hline Case study & 13 & 15 \\
\hline Citations & 103 & 132 \\
\hline Clarity & 109 & 139 \\
\hline Cohesion & 42 & 49 \\
\hline Complexity and simplicity & 45 & 50 \\
\hline Concision & 44 & 51 \\
\hline Conclusion & 51 & 54 \\
\hline Description & 74 & 96 \\
\hline English language skills & 37 & 40 \\
\hline Evidence and research & 102 & 128 \\
\hline Factual accuracy & 9 & 11 \\
\hline Figure & 46 & 74 \\
\hline Format and style & 107 & 138 \\
\hline Introduction & 52 & 60 \\
\hline Length & 28 & 30 \\
\hline Opinion & 34 & 43 \\
\hline Personal experience & 39 & 49 \\
\hline Plagiarism & 14 & 24 \\
\hline $\begin{array}{l}\text { Process to assign peer } \\
\text { reviewers }\end{array}$ & 4 & 4 \\
\hline Proofreading and grammar & 50 & 61 \\
\hline Provide examples & 37 & 51 \\
\hline Quotations & 22 & 24 \\
\hline Structure & 111 & 141 \\
\hline Title & 31 & 35 \\
\hline Topic & 102 & 136 \\
\hline $\begin{array}{l}\text { Peer-to-peer connections } \\
\text { (aggregated) }\end{array}$ & 511 & 3861 \\
\hline Connecting outside of class & 26 & 91 \\
\hline Disagreement & 25 & 49 \\
\hline $\begin{array}{l}\text { Feedback on Math Problem } \\
\text { Solving }\end{array}$ & 6 & 14 \\
\hline Feedback on Problem Solving & 9 & 19 \\
\hline $\begin{array}{l}\text { Goals or aspirations in course } \\
\text { discipline }\end{array}$ & 60 & 576 \\
\hline Introductions to peers & 55 & 784 \\
\hline $\begin{array}{l}\text { Offering moral or emotional } \\
\text { Support }\end{array}$ & 142 & 293 \\
\hline Offering peer review & 138 & 341 \\
\hline Offering tips or help to peers & 209 & 931 \\
\hline $\begin{array}{l}\text { Seeking moral or emotional } \\
\text { Support }\end{array}$ & 47 & 86 \\
\hline Seeking peer review & 100 & 133 \\
\hline Seeking tips or help from peers & 175 & 393 \\
\hline PIT Post goal priority & 0 & 0 \\
\hline 1 primary goal & 477 & 3366 \\
\hline
\end{tabular}




\begin{tabular}{|c|l|l|}
\hline 2 Secondary goal & 81 & 229 \\
\hline 3 Ancillary goal & 6 & 8 \\
\hline Post type & 0 & 0 \\
\hline Course experience discussion & 178 & 1040 \\
\hline Course experience question & 68 & 161 \\
\hline Course material discussion & 189 & 805 \\
\hline Course material question & 140 & 319 \\
\hline Spam or inappropriate & 9 & 14 \\
\hline Student challenges & 0 & 0 \\
\hline Lack of time and energy & 50 & 109 \\
\hline Less academically prepared & 26 & 91 \\
\hline Less or not self-directed & 39 & 65 \\
\hline
\end{tabular}




\section{Appendix B}

\section{Chemistry Writing Assignment}

Objective: The objectives of this assignment are:

1) to encourage you to learn more about the chemistry related to a specific topic that interests you through research and writing.

2) to allow you to learn more about diverse topics of interest to other students by reading, responding to, and reviewing their essays.

Assignment: Pick any topic related to chemistry that interests you (some global topics are listed below to give you ideas, but you do not have to restrict yourself to that list.) Since most of the global topics are much too broad for the length limit allowed, narrow your interest until the topic is unique and can be covered (with examples) in less than a couple of pages of writing.

Once you have a topic, write an essay in which you address the following questions:

- What are the chemicals and/ or chemical reactions involved with this topic?

- How does the chemistry involved with this topic relate to the material in the course?

- Are there economic or societal impacts of this chemistry? If so, then briefly describe aspects of ongoing debate, costs, etc.

- What some some questions for future research papers if you or someone else wanted to learn more about how chemistry intersects with this topic?

- Did this research lead you to formulate any new questions about the chemistry itself?

Individual Research Paper Guidelines and Requirements:

- Because other students will need to be able to read what you have written, the assignment must be submitted in English. If you are worried about grammar because English is not your native language, then please just note that right at the top of the essay and your peers will take into account the extra effort it requires to write in a foreign language.

- Think about what terms your classmates already know based upon what has been covered to date and what terms might need additional explanation.

- The final paper should be 400-600 words, not including references or 
tables and figures and their captions. There is no word count police, but please use this as a guideline for length.

- Be careful not to use the "cut and paste" method for your writing. Each sentence should be written in your own words, with appropriate references to the works of others if you are getting your ideas or information for that sentence from a source.

- Online references should be used, and these should be free and available to everyone with internet access (open source, no subscription required.) At least three distinct references must be included. Wikipedia and other encyclopedias should not be cited, but these can be a starting point for finding primary sources. Please be sure to cite your source websites. Please provide the references at the end of the essay as a numbered list, and insert the citation at the appropriate spot in the essay body (usually right after a sentence) using square brackets around the number that corresponds to the correct reference on the list.

- The paper can include up to 3 tables/figures. Tables and figures are optional, but might be helpful in conveying your ideas and analysis. Tables and figures should include citations to sources if they are not your intellectual property (As examples, a photograph that you take would not require citation as you would hold the copyright, but a photograph that you find on the web or in the literature would require citation. A graph or table that you pull straight from a source should cite that source explicitly in the figure caption; a graph or table that you construct yourself using data from multiple sources should cite the sources of the data with an indication that you own copyright to the graph or table itself.)

- The paper should include data and/or chemistry related to the topic and might also include an analysis of the impacts of the issue upon society (yourself and the community.) Political, economic, and/ or historical analysis may also be appropriate depending upon the topic. Every paper MUST contain some chemistry.

- Submission will be electronic, and submitted papers will be copied to the course forum as soon as the first peer feedback is received so that others may learn and continue the discussion. Author names will be posted with their writing on the forum as well. Including your name promotes accountability in your work and closer collaboration among peers.

Sample Writing and Sample Peer Feedback: Prof. Canelas has secured permission from a few real students from former courses to post their essays and sample peer feedback to help guide your work. These will be posted in a separate section under the "Reference Information" section on the course main page no later than the beginning of the third 
week of class.

Some Global Topic Suggestions: (In no particular order. Anything is fair game as long as it involves chemistry, so feel welcome to make up your own topic not related to this list. Again, please be sure to substantially narrow your topic, perhaps to a single molecule, concept, or event; these categories are much too broad but might give you some ideas of topics to explore that interest you.)

- Combustion Chemistry: Politics, Projections, and Pollution for Petroleum, Biofuels

- The Chemistry of the Senses: Taste, Odor, and/ or Vision

- History, Chemistry, and Future of Antibiotics

- The Sun, Moon, Stars, and Planets: Chemistry of Astronomy

- Water, Water, Everywhere: Anything related to H2O chemistry from water medical diagnostic imaging to acid rain

- Cradle to Grave: Polymers and Plastics

- The Evolution of Chemistry for Enhanced Technology: Lighter, Stronger, Faster, Cheaper, and Cleaner

- Chemistry, Politics, and Economics of Local Pollution Issues (can be in your local area or other locations of your choice)

- Elementary, My Dear Watson: Forensic Chemistry

- The Chemistry of Diabetes, Sugar, and/ or Sugar Substitutes (or pretty much any other disease, biological process, or food)

- Missing Important Food Chemicals: Scurvy, Rickets, Starvation!

- Genetic Engineering of Food (aka Messing with Molecules We Eat)

- Addictive Chemicals, both Legal and Illegal

- Chemistry of Art Preservation

- Dynamism, Diplomacy, and Disaster: Nuclear Energy, Weapons, and Waste

- Athletes on the Edge: Chemistry and Detection of Performance Enhancing Drugs in Sports

- Batteries: Portable Devices that Convert Chemical Energy to Electrical Energy

- Alternative Energy (Solar Cells, Fuel Cells)

- Chemistry of Archeology, such as Unlocking the Secrets of the Terra Cotta Warriors of Xian

- Chemistry and Controversies of Climate Change

- The Chemistry of Color

- Chemical communication: pheromones

- Poisoning: intentional or unintentional 


\section{Appendix C}

\section{Peer Feedback Guidelines for Chemistry Writing Assignment}

Read your peer's essay and comment on:

1. Strengths of the paper: what aspects of the paper did you particularly enjoy or feel were well done?

2. Areas for improvements or additions to the paper, ideally with specific suggestions.

3. Insights you learned from reading the paper or what you found to be the most interesting aspects of the topic.

Please give feedback in paragraph form rather than as single sentences underneath the guidelines. Please remember: we are not grading these essays with a score. Instead, we are learning about chemistry from each other through the processes of researching, writing, reading, and providing comments for discussion. 


\section{Appendix D}

\section{I am a Writer Assignment from English Composition}

Write a brief essay ( $\sim 300$ words) in which you introduce yourself as a writer to your classmates and instructor. How would you describe yourself as a writer? What are some of your most memorable experiences with writing? Please draw on your experiences with writing and refer directly to some of these as you introduce yourself as a writer. After you have written and posted your essay, please read and respond to two or three of your classmates' postings. 


\section{Appendix E}

\section{Four Major Writing Projects, English Composition}

\section{Project One: Critical Review}

The Uses and Limits of Daniel Coyle's "The Sweet Spot."

In this project, I will ask you to write a 600-800 word critical review of Coyle's article, summarizing the project in his terms, quoting and analyzing key words and passages from the text, and assessing the limits and uses of his argument and approach.

\section{Project Two: Analyzing a Visual Image}

In your second project, I will ask you to develop a 600-800 word analysis of a visual representation of your chosen field of expertise. I will ask you to apply Coyle's and Colvin's ideas, and the forum conversations by classmates, to examine how expertise in your chosen area is represented and how it reflects, modifies, and/ or challenges ideas about expertise: How is expertise represented visually? What does the image suggest about what it takes to be an expert in this field? How is expertise being defined in this image?

\section{Project Three: Case Study}

In this project, I will ask you to extend your work with Projects One and Two by researching additional scholarship about expertise in your chosen area, reading more texts about expertise theory through a crowd-sourced annotated bibliography (a collection of resources, with summaries, posted by all students), and applying those to a particular case study (example) of an expert or expertise in your field. I will ask you to extend these scholarly conversations through a 1000-1250 word case study in which you can articulate a position about expertise or an expert in the area of inquiry you have chosen.

\section{Project Four: Op-Ed}

Since the academic ideas are often made public (and arguably should be), I will ask you to write a two-page Op-Ed about a meaningful aspect of your chosen area of expertise: What aspects are important for others to consider? What advice would you have for people desiring to become an expert in this area? What are the politics and cultures involved with establishing and defining expertise in this particular area?

\section{Sample Full Project Assignment, English Composition, Project 3, Case Study}




\section{Project Components and Key dates}

Project 3 will be completed in sequenced stages so you can move through the writing process and have adequate time to draft and revise by integrating reader feedback.

- Contribute to our annotated bibliography on the discussion forums: (Weeks 68)

- First draft due, with "note to readers": May 13, 9:00 am EDT (-0400 GMT)

- Respond to Peers (formative feedback): May 20, 9:00 am EDT (-0400 GMT) Note: You MUST get your comments back to the writers on time so they can meet the next deadline!

- Reflect on Responding to Peers

- Revise and Edit: Feedback available beginning May 20, 10:00 am EDT (-0400 GMT)

- Final draft due, with reflection: May 27, 9:00 am EDT (-0400 GMT)

- Evaluate and respond to Peers (evaluative feedback): J une 3, 9:00 am EDT (0400 GMT)

- $\quad$ Reflect on Project 3

Purpose: Learn how to research an in-depth example of expertise.

\section{Overview}

Case studies offer academic writers the chance to research a particular example in a deep, sustained way, and then consider the ways in which that case study might offer generalizable conclusions. For Project 3, extend your work with Projects One and Two by researching additional scholarship about expertise in your chosen area, read more texts about expertise theory through a crowd-sourced annotated bibliography (a collection of resources, with summaries, posted by all students), and apply that research to a particular case study (example) of an expert or expertise in your field. Specifically, we will continue to work with the elements we learned in Units 1 and 2, as well as build on them by focusing on how to:

- conduct research;

- write an extended argument;

- develop an intertextual conversation;

- understand different limits of and uses for popular sources and scholarly sources;

- create effective introductions; and

- write strong conclusions. 


\section{Assignment}

For this third writing project, I am asking you to build on your work in Project 1 and Project 2, and extend our conversations about expertise through a 1000-1250 word case study in which you articulate a position about expertise or an expert in the area of inquiry you have chosen. Your case study can be about a particular person or aspect of expertise in your chosen area. Use this case study to generate an argument about expertise. See below for ideas about the questions you might use to develop your argument.

Here are a few examples of possible case studies, along with potential resources:

a. Area of Expertise: Software Engineering.

Potential Case Study: Leading Expert in Software Engineering

Potential Sources: biographical information about that expert; information about the institution in which he or she works; information about the elements of softwareengineering he or she has mastered or developed.

\section{b. Area of Expertise: Cooking}

Potential Case Study: Michelin Ratings

Potential Sources: information about the history of Michelin Ratings; information about the current restaurants named in the ratings; disagreements around Michelin; information about rating systems that compete with Michelin.

\section{c. Area of Expertise: American Civil War}

Potential Case Study: Reenactment Groups

Potential Sources: descriptions of various reenactment groups; history of these groups; structure, activities, and schedules for these groups.

For sample case studies, please visit our course's Readings \& Resources page. You will find that case studies appear in a variety of formats. You can choose the format that you believe fits best for your case study.

Your steps for this project include the following:

- Identify a potential case study you would like to use for Project 3. Remember that the process of research is sometimes recursive, and you might find through your research that you would like to change or modify your original idea for a case study. This is a natural part of the research process.

- Find and read texts about this case study. 
- Visit the Discussion Forum, Annotated Bibliography and contribute annotated entries; read through your classmates' contributions to see other potentially useful research. (See Annotated Bibliography Instructions for more specifics on this.) Using this research, draft and revise your Project 3 essay within the appropriate deadlines for drafts, peer feedback, and revision.

\section{$\underline{\text { Readers }}$}

Your readers will be interested in questions about expertise, but are perhaps unfamiliar with the texts you have read or the area of expertise you have chosen.

\section{Questions to Help You}

Consider the following questions as you develop your argument:

- What can we learn about expertise by researching a particular case study?

- What does it take to succeed based on this case study?

- What are the defining features of expertise based on this case study?

- What can you learn about expertise based on this case study?

- Based on this case study, how is expertise being defined?

- How might this case study reinforce, challenge, or otherwise modify our prior thinking about expertise, such as the ideas of Coyle, Colvin, or others?

- How might this case study raise new questions about expertise?

- What questions does the case study raise for you?

\section{Integrating Evidence and Citing the Evidence}

Integrate evidence into your essay by including quotes and/ or paraphrases from the research.

Strategies for effectively incorporating quotes and paraphrases are described in the video,

"Integrating Evidence." Refer to OWL for specifics on the school of citation you are choosing to write within. You should choose a school of citation with which you would like to gain more familiarity and/ or that seems most relevant for your future pursuits. Include a "Works Cited" or

"References" page at the end of your work listing all texts you have referred to.

\section{Submission Guidelines}

Post all documents to the appropriate Assignments section no later than the due date so your responders can read and send you comments for your final version. 


\section{Grading Criteria}

An excellent project will meet the following criteria, showing that you can:

- $\quad$ present the case study thoroughly

- conduct research and evaluate sources

- effectively use the case study to support and/ or develop your own argument

- effectively integrate evidence in the form of details about the case study, as well as quotes and paraphrases from sources

- employ scholarly conventions for citing sources, including in-text citations and works-cited page

- organize the essay clearly

- develop paragraphs that achieve paragraph unity

- create effective introductions and conclusions

- revise deeply as well as edit carefully

- include an effective title 


\section{Appendix F}

\section{Sample Formative and Evaluative Peer Feedback Rubrics, Project 3}

\section{Peer Response, Project 3, Draft 1: Case Study on Expertise (Formative Feedback)}

****Reading and Responding to Other Writers Makes You a Better Writer and Will Also Improve Your Own Project Draft****

Peer feedback is crucial to our work as writers: it helps the writer improve his or her draft and grow as a writer, but it also helps you, as a responder, improve your draft and advance more generally as a writer. I am asking you to respond to three people's drafts. For this first draft, provide formative feedback--that is, feedback that will help a writer improve and revise his or her draft. To do so, first review the goals of the assignment and our course's overall learning objectives, and then provide responses to the nine feedback questions below. Responding by the specified due date is crucial so that the writer can submit his or her next draft on time. Your classmates are depending on you!

\section{Providing Formative Feedback For Project 2, Draft 1}

Using the writer's “Note to Readers: My Queries," as well as our learning objectives/ criteria for this unit and the overall course (see above), answer each of the following questions so you can provide feedback to your colleague in order to help him or her improve this draft and grow as a writer:

1. Respond to the writer's "Note to Readers: My Queries"

2. Where does the writer offer details about the case study? Is this sufficient to convey the important aspects of the case study to readers who may not be familiar with this?

3. Where does the writer go beyond description to pose a question about expertise or to show how the case study reflects, contrasts, or modifies ideas about expertise?

4. Summarize in a sentence or two what the writer is arguing, if you can. If you cannot, say what the writer might do to make the argument more clear.

5. What evidence does the writer draw on to support and/ or develop his or her argument? Has the writer effectively integrated, discussed, and cited research? If not, say what the writer might do to integrate and cite research more effectively. 
6. Are there so many unconventional features in the writing (spelling, sentence structure, vocabulary, and so on) that you found them interfering with your reading? Identify in particular one of these features so the writer can focus on it for his or her revision.

7. Did you find the introduction effective? If so, please describe what features make them effective. If not, make a few suggestions for how the writer can improve it.

8. Did you find the conclusion effective? If so, please describe what features make them effective. If not, make a few suggestions for how the writer can improve it.

9. What did you like best about this essay?

10. What did you learn about your own writing/your own project based on responding to this writer's project?

\section{Peer Response, Project 3, Final Version: Case Study on Expertise (Evaluative Feedback)}

****Reading and Responding to Other Writers Makes You a Better Writer and Will Also Improve Your Own Project Draft****

Evaluative feedback enables writers to reflect on not only the writing project, but also themselves as writers. Providing effective evaluative feedback will enable your colleagues to move forward to Project 4 and advance as writers. Providing evaluative feedback will enable you to grow as a writer as you reflect on what another writer's project can teach you about writing.

\section{Providing Evaluative Feedback For Project 3, Final Version}

Using the grading criteria above, the writer's “Note to Readers," and our overall learning objectives/criteria for this unit, you will be scoring your colleague's projects on a 6-point scale in order to help them improve as writers for subsequent writing occasions.

Think of the 6-point scale as two halves:

a top half of 4, 5, or 6 representing different levels of successful projects and a lower half of 1, 2, and 3 representing different levels of unsuccessful projects. You can think of a paper scoring 5 as the center of success and one scoring 2 as the center score for lack of success, with the other scores as a minus or plus. Thus a score of 
4 is successful, but marginally so, a kind of 5-. A score of 6 is exceptionally successful, a kind of 5+. Only one whole number, without pluses or minuses, can be entered on the SCORE line. Your score will be combined with three other peer scores to obtain a grade for the writer's project.

Score of 6: This project will meet all criteria and goals for unit 3 and be very clear and well written. It need not be perfect but it will be well reasoned, show a deep understanding of the case study, evaluates and discusses relevant research, and shows a compelling discussion of how the case study reflects, contrasts, or modifies our thinking about expertise. The project uses the case study to raise new questions about expertise. The introduction and conclusion are strong. Evidence is integrated effectively, and the title is strong. Citations are mostly correct.

Short description: Exceptionally successful

Score of 5: This project not only presents the case study, but also uses it to make an argument about expertise. It is clear and well written. The project includes relevant research. Paragraphs are unified and the paper is organized clearly. The introduction and conclusion are strong. Evidence is integrated effectively, and the title is strong. Citations are mostly correct.

Short description: Successful

Score of 4: This project describes the case study in an organized way, but it does not offer a thorough understanding of it, and has little or nothing to say about its relation to the issue of expertise. It may have a few unconventional features of written English, such as vocabulary, sentence construction, etc., but these do not for the most part interfere with the communication of the writer's ideas. It is for the most part clearly written. Paragraphs are mostly organized clearly and unified. Research may be a bit limited, and evidence is integrated effectively some of the time. Distinctions are rarely made among the sources and quotations are sometimes inserted without being discussed. The introduction and/ or conclusion are somewhat effective. Citations

are present and mostly correct. The title is somewhat effective.

Short description: Successful, but marginally so

Score of 3: This project shows only a superficial understanding of the case study and limited description of it. It may have some unconventional features of written English, such as vocabulary, sentence construction, etc., that interfere with the communication of the writer's ideas. It offers little by way of argument. The project uses little research and does not evaluate or discuss the sources. Evidence is only occasionally integrated effectively, and/ or not much evidence is used. Citations are often incorrect. The introduction and / or conclusion are present, but not effective. The title is largely ineffective. 
Short description: Unsuccessful, but marginally so

Score of 2: This project pays little attention to the case study or shows little understanding of it. It offers very little by way of argument, and hardly any research. It may also contain some unconventional features of written English, such as vocabulary, sentence construction, or other features that interfere with the communication of the writer's ideas. The essay is not organized clearly, and the paragraphs often are not unified. Evidence is for the most part not integrated effectively, and/ or very little evidence is used. Citations are mostly incorrect or absent. The introduction and / or conclusion are not effective. The title is ineffective.

Short description: Unsuccessful

Score of 1: This project has misunderstood the nature of the assignment or the meaning of the case study and presents many unconventional features of written English, such as vocabulary, sentence construction, or other features that interfere with the communication of the writer's ideas. Evidence is not integrated effectively, and/ or no evidence is used. The paper is disorganized and paragraphs are not unified. Citations are incorrect or absent. The title is absent or ineffective.

Short description: Extremely Unsuccessful

\section{Fill in the following boxes:}

What overall comments do you have for the writer as he or she moves on to Project 4 ?

What did you learn about you your own writing based on reading and evaluating this writer's project? 


\section{Appendix G}

\section{Final Reflective Essay Assignment, English Composition}

Reflection is crucial to growing as a writer. Reflection helps you consider how you can apply what you have learned from one experience to subsequent writing and nonwriting occasions. Now that you have nearly finished this course, please reflect on what you have learned about yourself as writer. This quiz is credit/ no credit: if you complete it, you get credit; if you do not complete it, there will be no credit. Part of the quiz asks you to cut and paste text from your course writing, so please have the following available as you complete the Reflection: Drafts and Final Versions of Projects 1-4, Feedback to and from Colleagues, Forum Comments, and Reflective Quizzes. The quiz is due J une 12, 9:00 a.m. GMT -0400. You may not apply late days.

The following are our course learning objectives:

Sum marize, analyze, question, and evaluate written and visual texts

Argue and support a position

Recognize audience and disciplinary expectations

Identify and use the stages of the writing process

Identify characteristics of effective sentence and paragraph-level prose

Apply proper citation practices

Discuss how to transfer and apply your writing knowledge to other writing occasions Imagine that you have compiled a portfolio of all your work from this course (Drafts and Final Versions of Projects 1-4, Feedback to and from Colleagues, Forum Comments, and Reflective Quizzes) and you are preparing to share it with others. These potential readers might be administrators at a school you are applying to, current or potential employers, friends, or other acquaintances. Your task is to write a cover letter that introduces your work and makes an argument about your understanding and achievement of the course learning objectives.

In the space provided here, discuss what you have learned in this course and choose 2-4 of our course learning objectives, describing each objective and referring specifically to particular passages from your coursework that demonstrate your progress towards and/ or struggles with that objective. Indicate why you have chosen those objectives as the most important for you. Cut and paste specific portions of your coursework, and use them as evidence for your argument. In this way, by having an introduction, argument, evidence, and conclusion, your "portfolio cover letter" will both discuss and 
demonstrate how effectively you have achieved the goals of the course. When referring to your work, indicate clearly the piece of writing (i.e., Project 3) and page number(s) for your readers' ease of reference.

Length: $\sim 500-750$ words

(C) Comer, Clark, Canelas

\section{Athabasca University $\mathbf{n}$}

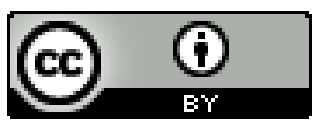

This work is licensed under a Creative Commons Attribution 4.0 International License. 